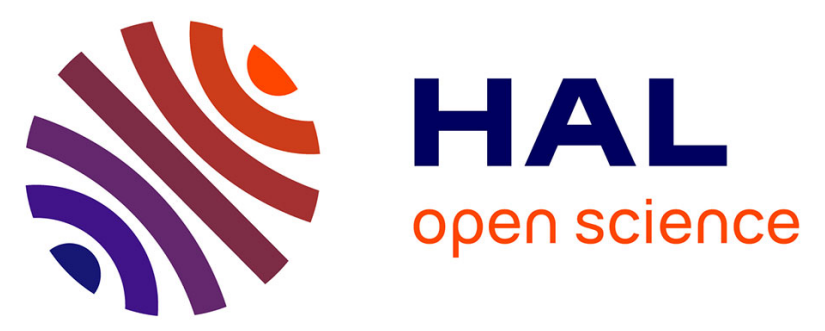

\title{
Thiol groups controls on arsenite binding by organic matter: New experimental and modeling evidence
}

Charlotte Catrouillet, Mélanie Davranche, Aline Dia, Martine Bouhnik-Le Coz, Mathieu Pédrot, Rémi Marsac, Gérard Gruau

\section{- To cite this version:}

Charlotte Catrouillet, Mélanie Davranche, Aline Dia, Martine Bouhnik-Le Coz, Mathieu Pédrot, et al.. Thiol groups controls on arsenite binding by organic matter: New experimental and modeling evidence. Journal of Colloid and Interface Science, 2015, 460, pp.310-320. 10.1016/j.jcis.2015.08.045 . insu-01187067

\section{HAL Id: insu-01187067 https://hal-insu.archives-ouvertes.fr/insu-01187067}

Submitted on 26 Aug 2015

HAL is a multi-disciplinary open access archive for the deposit and dissemination of scientific research documents, whether they are published or not. The documents may come from teaching and research institutions in France or abroad, or from public or private research centers.
L'archive ouverte pluridisciplinaire HAL, est destinée au dépôt et à la diffusion de documents scientifiques de niveau recherche, publiés ou non, émanant des établissements d'enseignement et de recherche français ou étrangers, des laboratoires publics ou privés. 


\section{Thiol groups controls on arsenite binding by organic matter:}

\section{new experimental and modeling evidence}

Charlotte Catrouillet ${ }^{\mathrm{a}^{*}}$, Mélanie Davranche ${ }^{\mathrm{a}}$, Aline Dia ${ }^{\mathrm{a}}$, Martine Bouhnik-Le Coz $^{\mathrm{a}}$, Mathieu Pédrot ${ }^{\mathrm{a}}$, Rémi Marsac ${ }^{\mathrm{b}}$, Gérard Gruau ${ }^{\mathrm{a}}$

\footnotetext{
a Géosciences Rennes UMR 6118, Université Rennes 1, CNRS, 35042 Rennes cedex, France

${ }^{\mathrm{b}}$ Ecole Nationale Supérieure de Chimie de Rennes, 135708 Rennes cedex 7, France

* Corresponding author: charlotte.catrouillet@univ-rennes1.fr, +33 (0)2 23235458
}

Keywords: Arsenic(III), humic substances, thiol, binding, sorption, PHREEQC-Model VI, PHREEPLOT

\section{ABSTRACT}

Although it has been suggested that several mechanisms can describe the direct binding of As(III) to organic matter (OM), more recently, the thiol functional group of humic acid (HA) was shown to be an important potential binding site for As(III). Isotherm experiments on As(III) sorption to HAs, that have either been grafted with thiol or not, were thus conducted to investigate the preferential As(III) binding sites. There was a low level of binding of As(III) to $\mathrm{HA}$, which was strongly dependent on the abundance of the thiols. Experimental datasets were used to develop a new model (the modified PHREEQC-Model VI), which defines HA as a group of discrete carboxylic, phenolic and thiol sites. Protonation/deprotonation constants were determined for each group of sites $\left(\mathrm{pK}_{\mathrm{A}}=4.28 \pm 0.03 ; \Delta \mathrm{pK}_{\mathrm{A}}=2.13 \pm 0.10 ; \mathrm{pK}_{\mathrm{B}}=7.11 \pm\right.$ $0.26 ; \Delta \mathrm{pK}_{\mathrm{B}}=3.52 \pm 0.49 ; \mathrm{pK}_{\mathrm{S}}=5.82 \pm 0.052 ; \Delta \mathrm{pK}_{\mathrm{S}}=6.12 \pm 0.12$ for the carboxylic, phenolic and thiols sites, respectively) from HAs that were either grafted with thiol or not. The $\mathrm{pK}_{\mathrm{s}}$ value corresponds to that of single thiol-containing organic ligands. Two binding models were tested: the Mono model, which considered that $\mathrm{As}(\mathrm{III})$ is bound to the HA thiol site as monodentate complexes, and the Tri model, which considered that $\mathrm{As}(\mathrm{III})$ is bound as tridentate complexes. A simulation of the available literature datasets was used to validate 
the Mono model, with $\log \mathrm{K}_{\mathrm{MS}}=2.91 \pm 0.04$, i.e. the monodentate hypothesis. This study highlighted the importance of thiol groups in OM reactivity and, notably, determined the As(III) concentration bound to OM (considering that Fe is lacking or at least negligible) and was used to develop a model that is able to determine the As(III) concentrations bound to OM.

\section{Introduction}

According to the World Health Organization (WHO), arsenic (As) is known to be a major poison in the world. Even at low concentrations, As causes serious damage to human health such as cutaneous lesions (black foot disease), cancers (skin, lung, bladder, etc.), cardiovascular diseases, respiratory problems, etc. The main contamination process occurs through the consumption of As-contaminated water and the ingestion of contaminated crops (such as rice). Arsenic-contaminated water affects millions of people in Argentina, Bangladesh, Chili, China, United States, India, Mexico, etc. The abundance of As in the soil and water primarily depends on the geology and human activity (historic or current). As(III) is the most toxic inorganic form. Many studies have been performed to understand the mechanisms responsible for the contamination of water by As [1-5]. Wetlands and floodplains have been highlighted as a source of As for the surrounding environments [6-8]. Arsenic-rich sediments, in which As is bound to Fe-oxyhydroxides, are deposited in riparian wetlands and floodplains during flooding events. In the anoxic, organic-rich environments that characterize these zones, Fe-oxyhydroxides are reductively dissolved and the associated As is released into the soil solutions, and are then available for transfer in the underlying aquifers. However, there is a lack of information regarding the fate of As in this type of $\mathrm{Fe}(\mathrm{II})$, OM-rich solution. In such environments, OM is often discussed as a source of carbon for the heterotrophic bacteria able to reductively dissolve Fe-oxyhydroxides and solubilize the associated elements, such as As, or to directly reduce $\mathrm{As}(\mathrm{V})$ to $\mathrm{As}(\mathrm{III})$ in their detoxification metabolism [9-13]. Organic matter is also shown to be a competitor of anions, such as arsenite, for their binding to the functional sites of Fe-oxyhydroxides [4,14-16]. 
Several studies present $\mathrm{OM}$ as a possible ligand for As(III), but no consensus exists about the nature of the exact direct or indirect mechanisms involved. Thanabalasingam and Pickering and Warwick et al. proposed that As(III) is bound to humic acid (HA) through cationic bridges involving $\mathrm{Al}, \mathrm{Fe}$ and $\mathrm{Ca}$ impurities occurring in $\mathrm{HA}$ or by direct binding through HA amino groups [17,18]. Using Suwannee River HA (SRHA), Buschmann et al. and Lenoble et al. hypothesized that As(III) could be bound to HA through its carboxyl and phenolic functional groups $[19,20]$. Alcohols are able to bind As(III) by losing an $\mathrm{OH}^{-}[21]$, suggesting that As(III) could be bound to phenolic groups of OM. Regarding the weaker and more abundant carboxylic groups, Buschmann et al. suggested that binding could occur through the formation of $\mathrm{H}$-bridges between the $\mathrm{OH}^{-}$group of $\mathrm{As}(\mathrm{OH})_{3}$ and the $=\mathrm{O}$ part of the group without any $\mathrm{OH}$ loss. In their study, these authors also proposed that Fe might act as a bridge between As(III) and HA [19]. Liu and Cai and Fakour and Lin, through experimental and modeling approaches, hypothesized that As(III) was bound to HA by two kinds of binding sites, one strong and one weak $[22,23]$.

More recently, spectroscopic and experimental studies have suggested that thiol $\left(\mathrm{SH}^{-}\right.$ ) could play an important role in As(III) binding to peat and HA $[24,25]$. These authors demonstrated that As(III) is bound to tridentate or monodentate complexes via thiol groups, depending on the selected peat and HA. By spiking HA and peat with bisulfides, Hoffmann et al. showed that As(III) binding increased with increasing bisulfide concentrations [25]. Using EXAFS, they provided evidence of the formation of a monodentate thiol-As(III) complex on S(-II)-spiked HA and peat. Conversely, Langner et al. used EXAFS data to show that As(III) is bound to three $S$ in peat from Gola di Lago (Switzerland) [24]. The different complexes might be explained by differences in the origin of the organic matter (OM). In the Gola di Lago peatland, peat was formed in an As-enriched environmental context. Arsenic was absorbed by plants and/or microorganisms, which were the precursors of the peat. In these precursors, As was bound to proteins, enzymes, etc., mainly as tridentate complexes with the $\mathrm{SH}^{-}$group of cystein; a configuration that seems to be conserved in the peat structure [25]. The binding of $\mathrm{As}(\mathrm{III})$ with thiol is not surprising considering that $\mathrm{As}(\mathrm{III})$ is bound to 
dithiol and trithiol sites in many proteins and peptides [26-33], either completely or partly inhibiting their specific actions in the body.

Here, we present a new contribution to evaluate the role of thiol sites in the binding of As(III) to OM. More specifically, considering the recent spectroscopic studies, we tried to determine the mechanisms of complexation between $\mathrm{As}(\mathrm{III})$ and the thiol groups in $\mathrm{HA}$ (the formation of mono- or tridentate complexes), using experimental and modeling approaches. Arsenic(III) was reacted with three samples of HA containing different concentrations of thiol sites. The experimental dataset was subsequently used to test the hypothesis of As(III)-HA binding through mono or tridentate complexes via HA thiol groups, using a combination of the PHREEPLOT (fitting program) and PHREEQC-Model VI programs. No model is currently available in the literature to describe the interactions between As(III) and organic matter. In a first step, the thiol groups had to be described and their binding parameter was introduced in PHREEQC-Model VI. Finally, the extrapolated binding parameters from the hypothesis of mono- or tridentate As(III)-thiol (HA) complexes were tested using the whole datasets available in the literature to identify the more valuable binding mechanisms. The goal of the model developed in the present study is to determine the speciation of As(III) in OM-rich water.

\section{Experimental, analytical and modeling methods}

\subsection{Reagents and materials}

All aqueous solutions were prepared with analytical grade Milli-Q water (Millipore). The As(III) solutions were prepared with sodium arsenite $\left(\mathrm{NaAsO}_{2}\right)$ from Sigma Aldrich. The $\mathrm{S}(-\mathrm{II})$ solution was prepared with sodium sulfide nonahydrate $\left(\mathrm{Na}_{2} \mathrm{~S} .9 \mathrm{H}_{2} \mathrm{O}\right)$ from Sigma Aldrich. $\mathrm{NaOH}, \mathrm{HCl}$ and $\mathrm{HNO}_{3}$, all sub-boiling ultrapure grade, came from Fisher Chemical, Merck and VWR, respectively.

Humic acids corresponded to the standard HA purified Leonardite from the International Humic Substance Society (IHSS) and the Aldrich HA (AHA) from Sigma Aldrich, which have different concentrations of $S$. To remove humins from the humic and fulvic acids, 
AHA was purified (PAHA) using the method described by Vermeer et al. [34]. Prior to the experiments, molecules $<10 \mathrm{kDa}$ were removed using a Labscale TFF system equipped with a Pellicon XL membrane (PGCGC10, Millipore ${ }^{T M}$ ) for the two standard solutions used (Leonardite and $\mathrm{AHA}$ ).

All materials were soaked in $10 \% \mathrm{HNO}_{3}$ and then rinsed with deionized water twice overnight.

\subsection{Experimental setup}

Thiol grafting experiment. To obtain HA with different concentrations of thiol groups $(\mathrm{S}(-\mathrm{II})), \mathrm{S}(-\mathrm{II})$ were sorbed to Leonardite using a dialysis bag (pore size $=12-14 \mathrm{kDa}$ ) at a ratio $[\mathrm{S}(-\mathrm{II})] /[\mathrm{DOC}] \approx 6 \mathrm{mmolS} / \mathrm{molC}$, as was done previously in a precedent study [25]. No grafting was performed for PAHA because of its natural high concentration in S. Humic acids and the S(-II) solutions were placed inside the membrane, whereas S(-II) was outside. The $\mathrm{pH}$ was maintained at 6 and the ionic strength (IS) was fixed at $0.05 \mathrm{M}$ with $\mathrm{NaCl}$. The Leonardite grafted with thiol groups will be noted S(-II)-Leonardite hereafter. To prevent any oxidation of $\mathrm{S}(-\mathrm{II})$, the experiments were performed in a Jacomex isolator glove box. The concentration of S(-II) outside of the membrane was monitored using an ionometric method. Ten $\mathrm{mL}$ of solution was sampled and mixed with SAOB (Sulphide AntiOxidant Buffer) at a 1:1 ratio. The concentration of $S(-I I)$ was measured outside of the glove box using a sulfide combined electrode (9616BNWP from Thermo Scientific). The grafting experiment continued until all S(-II) had disappeared from the solution outside of the membrane.

Humic acid titrations. Acid-base potentiometric titrations of the Leonardite and S(II)-Leonardite were performed using an automatic $\mathrm{pH}$ stat titrator (Titrino 194, Metrohm) equipped with burettes of $0.1 \mathrm{M} \mathrm{NaOH}$ and $\mathrm{HCl}$ solutions. The detailed method is described elsewhere [35]. Fifty $\mathrm{mL}$ of $1 \mathrm{~g} \mathrm{~L}^{-1}(\mathrm{DOC})$ was titrated at two IS, 0.001 and $0.01 \mathrm{M} \mathrm{NaCl}$ with $0.1 \mathrm{M}$ of the $\mathrm{NaOH}$ and $\mathrm{HCl}$ solutions. Because the addition of $\mathrm{NaOH} / \mathrm{HCl}$ continuously modified the IS, this latter was re-calculated for each titration point and used to calculate the $\mathrm{H}^{+}$and $\mathrm{OH}^{-}$concentrations. To avoid any oxidation and carbonate addition, the solutions 
were continuously bubbled with nitrogen $\left(\mathrm{N}_{2}\right)$. To prevent any hysteresis, three titrations were performed, one after another. Only the second titration was used for the modeling calculations. The HA charge was calculated as follows:

$$
\mathrm{Q}=[\text { Acid }]-[\text { Base }]-\left(\left[\mathrm{H}^{+}\right]-\left[\mathrm{OH}^{-}\right]\right)
$$

with [Acid], [Base], $\left[\mathrm{H}^{+}\right]$and $\left[\mathrm{OH}^{-}\right]$equal to the concentration of $\mathrm{HCl}$ and $\mathrm{NaOH}$ added, and where free $\mathrm{H}^{+}$is calculated as $\left[\mathrm{H}^{+}\right]=\frac{10^{-\mathrm{pH}}}{\gamma\left(\mathrm{H}^{+}\right)}$and free $\mathrm{OH}^{-}$is calculated as $\left[\mathrm{OH}^{-}\right]=\frac{10^{(-14+\mathrm{pH})}}{\gamma\left(\mathrm{OH}^{-}\right)}$.

As(III)-HA binding experiments. A standard batch equilibrium method was used. Three adsorption isotherm experiments were carried out with 5 to $50 \mu \mathrm{g} \mathrm{L}^{-1}$ of $\mathrm{As}(\mathrm{III})$ and 55.76, 50.12 and $56.02 \mathrm{mg} \mathrm{L}^{-1}$ of average dissolved organic carbon (DOC) for Leonardite, S(II)-Leonardite and PAHA, respectively. To ensure anoxic conditions, experiments were performed in a Jacomex isolator glove box. The $\mathrm{pH}$ was fixed at 6 with ultrapure $\mathrm{HCl}$ and $\mathrm{NaOH}$. The $\mathrm{pH}$ was monitored with a multi-parameter Consort C830 analyzer equipped with a combined electrode from Bioblock Scientific (combined Mettler InLab electrode). Calibrations were performed with WTW standard solutions $\left(\mathrm{pH}=4.01\right.$ and 7.00 at $\left.25^{\circ} \mathrm{C}\right)$. The accuracy of the $\mathrm{pH}$ measurements was $\pm 0.05 \mathrm{pH}$ units. The $[\mathrm{As}(\mathrm{III})]_{\text {tot }}, \mathrm{pH}$ and $\mathrm{DOC}$ values used in these experiments corresponded to values that can be encountered in reduced wetland water $[4,36]$. The IS of all experiments was fixed at $0.05 \mathrm{M}$ with $\mathrm{NaCl}$ electrolyte solution. Experimental solutions were stirred for $48 \mathrm{~h}$ to reach equilibrium (determined from preliminary kinetic experiments). Then, $15 \mathrm{~mL}$ of solution was sampled and ultrafiltrated at 5 kDa (Vivaspin VS15RH12, Sartorius) by centrifugation at $2970 \mathrm{~g}$ for $30 \mathrm{~min}$ under $\mathrm{N}_{2}$ atmosphere. Ultracentrifugation cells were previously washed with Milli-Q water to obtain a DOC concentration $<1 \mathrm{mg} \mathrm{L}^{-1}$ in the ulltrafiltrate. Each isotherm experiment was conducted in triplicate.

\subsection{Chemical analyses}

All measurements were performed at Géosciences Rennes, University of Rennes I, France. DOC concentrations were determined using an organic carbon analyzer (Shimadzu TOC-V CSH). The accuracy of the DOC measurements was estimated at $\pm 5 \%$ for all 
samples using a standard solution of potassium hydrogen phtalate. Arsenic concentrations were determined by ICP-MS using an Agilent Technologies 7700x at Géosciences Rennes. All samples were previously digested twice with $14.6 \mathrm{~N} \mathrm{HNO}_{3}$ and $\mathrm{H}_{2} \mathrm{O}_{2}$ ultra-pure grade at $90^{\circ} \mathrm{C}$, then evaporated to complete dryness and finally resolubilized with $\mathrm{HNO}_{3}$ at $0.37 \mathrm{~mol} \mathrm{~L}^{-}$ ${ }^{1}$ to avoid any interference with DOC during the analysis. ICP-MS analyses were carried out using a He gas collision cell to reduce the ${ }^{40} \mathrm{Ar}^{35} \mathrm{Cl} /{ }^{75} \mathrm{As}$ ratio, allowing a low detection limit to be reached for the As analysis (LD As: $0.003 \mu \mathrm{g} \mathrm{L}^{-1}$ ). Instrumental and data acquisition parameters can be found in the supporting information SI 1. Quantitative analyses were performed using a conventional external calibration procedure (seven external standard multi-element solutions - Inorganic Venture, USA). A mixed solution of rhodium-rhenium at $300 \mathrm{ppb}$ was used as an internal standard for all measured samples to correct any instrumental drift and matrix effects. Calibration curves were calculated from the intensity ratios between the internal standard and the analyzed elements. A SLRS- 5 water standard was used to check the accuracy of the measurement procedure, and the instrumental error on the As analysis was established as below 5\%. Chemical blanks of As were below the detection limit $\left(0.003 \mu \mathrm{g} \mathrm{L}^{-1}\right)$, and were thus considered as negligible.

To ensure that no oxidation occurred during the experiments, the concentrations of $\mathrm{As}(\mathrm{III})$ and $\mathrm{As}(\mathrm{V})$ were checked. The As species were separated and the As(III) concentrations were determined in the ultrafiltrate ([As(III) $\left.]_{\mathrm{UF}}\right)$ through High Performance Liquid Chromatography (HPLC-Agilent 1260 Infinity) equipped with an anion exchange resin column (Agilent G3154-65001) coupled with ICP-MS. Quantitative analyses were performed using an injection of mixed standard solutions As(III, V) (Inorganic venture, USA) to determine the calibration curves. The total As concentrations in the mixed As(III)-HA solutions were only measured by ICP-MS using the above described procedure (with no estimation of the speciation). The HPLC column retains OM, which prevents any quantitative measurement of $\mathrm{As}(\mathrm{III})$ in this fraction from being taken. The accuracy of the $[\mathrm{As}(\mathrm{III})]_{\mathrm{UF}}$ and $[\mathrm{As}(\mathrm{III})]_{\text {tot }}$ measurements was estimated at less than $5 \%$ above a concentration of $\mathrm{As}(\mathrm{III})$ of 1 $\mu \mathrm{g} \mathrm{L}^{-1}$ (all samples). The As(III) concentrations in the ultrafiltrates were assumed to be 
inorganic As(III), whereas $\mathrm{As}(\mathrm{III})$ bound to $\mathrm{HA}(\mathrm{As}(\mathrm{III})-\mathrm{HA})$ was considered to be in the retentate fraction $>5 \mathrm{kDa}$. The fraction of $\mathrm{As}(\mathrm{III})$ bound to $\mathrm{HA}([\mathrm{As}(\mathrm{III})-\mathrm{HA}])$ was calculated as $[\mathrm{As}(\mathrm{III})-\mathrm{HA}]=[\mathrm{As}(\mathrm{III})]_{\mathrm{tot}}-[\mathrm{As}(\mathrm{III})]_{\mathrm{uF}}$, with $[\mathrm{As}(\mathrm{III})]_{\mathrm{tot}}$, the As concentration in the HA-As(III) solutions prior to ultrafiltration and $[\mathrm{As}(\mathrm{III})]_{\mathrm{UF}}$, the As concentration in the ultrafiltrate as determined with the ICP-MS.

The amounts of S and organic $\mathrm{C}$ in Leonardite and S(-II)-Leonardite and PAHA were determined at the "Laboratoire d'analyses des Sols d'Arras" (INRA, Arras, France) by dry combustion (ISO 10694) and ICP-AES (ISO 22036), respectively.

\subsection{Determination of the PHREEQC-Model VI binding parameters}

\subsubsection{Thiol implementation in PHREEQC-Model VI and the models used}

A new model was developed to implement the thiol groups in PHREEQC-Model VI. PHREEQC-Model VI described humic substances as a set of discrete functional sites that can be divided into groups of weak and strong sites [37]. Weak sites are usually assumed to be carboxyl groups, whereas strong sites are generally assumed to consist of phenolic and $\mathrm{N}$-containing sites. In the original Model $\mathrm{VI}$, the binding of metals by humic substances occurs through eight discrete sites: four weak sites, named A sites and four strong sites, named B sites. In the present study, to implement the thiol group, we added four thiol groups, named $S$ sites. The abundances of the type $A, B$ and $S$ sites are named $n_{A}, n_{B}$ and $n_{S}(m o l g$ ${ }^{1}$ ), respectively. The intrinsic proton dissociation constants for the type A, B and S sites and their distribution terms are $\mathrm{pK}_{\mathrm{A}}, \mathrm{pK}_{\mathrm{B}}, \mathrm{pK}_{\mathrm{S}}, \Delta \mathrm{pK}_{\mathrm{A}}, \Delta \mathrm{pK}_{\mathrm{B}}$ and $\Delta \mathrm{pK}_{\mathrm{S}}$, respectively. The fractions of sites that can make bidentate sites and tridentate sites are named $f_{B}$ and $f_{T}$ and are equal to 0.5 and 0.065 , respectively [37]. The abundances calculated for the 84 sites (monodentates, bidentates and tridentates) are given in supporting information SI 2 and 3.

The proton association/dissociation equations and calculations of pK (equilibrium constant) for the 12 groups (carboxylic, pheolic and thiol) are described in the supporting information SI 4. The protonation/deprotonation of the bidentates and tridentates are 
described as the decomposition of both protonation/deprotonation of the monodentates and the associated pK. For example, for the bidentate $\mathrm{Ha} \_\mathrm{ab}$, the reaction and pK are:

$$
\begin{aligned}
& \text { Ha_abH } 2=H a \_a b H-H^{+} \quad \mathrm{pK}=\mathrm{pK}(\mathrm{a})=\mathrm{pK}_{\mathrm{A}}-\frac{\Delta \mathrm{pK}_{\mathrm{A}}}{2} \\
& \mathrm{Ha} \_\mathrm{abH}=\mathrm{Ha} \_a b^{2-}+\mathrm{H}^{+} \quad \mathrm{pK}=\mathrm{pK}(\mathrm{b})=\mathrm{pK}_{\mathrm{A}}-\frac{\Delta \mathrm{pK}_{\mathrm{A}}}{6} .
\end{aligned}
$$

Ion sorption by humic substances is described by the specific complexation parameters $\log \mathrm{K}_{M A}$, $\log \mathrm{K}_{M B}$ and $\log \mathrm{K}_{\mathrm{MS}}$ for the carboxylic, phenolic and thiol sites, respectively. In this study, only the binding of the As(III)-thiol groups was studied, and therefore, only the binding parameter log $\mathrm{K}_{\mathrm{MS}}$ was determined. It is important to note that the binding reaction of each thiol with $\mathrm{As}$ (III) is characterized by a stability constant log $\mathrm{K}$, where $\log \mathrm{K}_{\mathrm{MS}}$ is the binding parameter for all the HA thiol sites defined in the modified PHREEQCModel VI. Two models of As(III) binding by HA were tested. They consisted of $\mathrm{As}(\mathrm{OH})_{3}$ binding by HA: (i) as monodentate complexes via one HA thiol site (Mono Model) and (ii) as tridentate complexes via three HA thiol sites (Tri Model). The Mono model is based on the spectroscopic results obtained elsewhere [25], showing 0.5 to $1.5 \mathrm{~S}$ in the first neighbor shell of As(III) bound to HA. The Tri model is based on the 1:3 complexes evidenced in the binding of $\mathrm{As}(\mathrm{III})$ with proteins [26-33,38]. The binding of $\mathrm{As}(\mathrm{III})$ with proteins is described as a deprotonation of three thiol groups in the cystein units and the loss of the three $\mathrm{OH}^{-}$in $\mathrm{As}(\mathrm{OH})_{3}$. The same mechanism was used in a study on $\mathrm{As}(\mathrm{OH})_{3}$ complexation to thiol grafted amberlite resin [39]. In the Mono model, only monodentates with thiol sites are defined, therefore, only four log $\mathrm{K}$ were fitted. The binding mechanism of $\mathrm{As}(\mathrm{OH})_{3}$ by monodentate complexes with HA was adapted for the binding of a neutral species and was described by the following reaction for the binding of $\mathrm{As}(\mathrm{OH})_{3}$ by the site $\mathrm{i}$ :

$$
\mathrm{Ha} \_\mathrm{iH}+\mathrm{As}(\mathrm{OH})_{3}=\mathrm{Ha} \_\mathrm{iAs}(\mathrm{OH})_{2}+\mathrm{H}_{2} \mathrm{O} \quad \log \mathrm{K}(\mathrm{i})=\log \mathrm{K}_{\mathrm{MS}}-\frac{\Delta \mathrm{LK}_{15}}{2}
$$

The other reactions describing the binding of $\mathrm{As}(\mathrm{OH})_{3}$ by monodentate complexes are described in the supporting information SI 5. In the Tri model, As is bound as tridentate with only three thiol groups (i.e. no tridentate with a combination of thiol, carboxylic and phenolic 
sites), therefore, only four log $\mathrm{K}$ were fitted. The binding mechanism between the ijk site and $\mathrm{As}(\mathrm{OH})_{3}$ is written as:

$$
\mathrm{Ha} \_\mathrm{ijkH} H_{3}+\mathrm{As}(\mathrm{OH})_{3}=\mathrm{Ha} \_\mathrm{ijkAs}+3 \mathrm{H}_{2} \mathrm{O} \quad \log \mathrm{K}(\mathrm{ijk})=3 * \log K_{\mathrm{MS}}-\frac{\Delta \mathrm{LK}_{1 \mathrm{~s}}}{2}(\mathrm{Eq} .5)
$$

The other reactions concerning the binding mechanisms between the tridentate sites and $\mathrm{As}(\mathrm{OH})_{3}$ are described in the supporting information SI 5.

\subsubsection{Electrostatic model}

Previous studies, where Models V, VI or VII were coupled to PHREEQC, attempted to convert this empirical electrostatic humic ion-binding model into the diffuse layer model (DLM) formalism [40-44]. This type of conversion requires the calculation of a surface area (A) that depends on the ionic strength similar to the calculations made for polyelectrolytes such as polyacrylic acid [45]. However, these approaches usually lead to surface areas that are physically unrealistic (e.g. $A_{H A}>10^{4} \mathrm{~m}^{2} \mathrm{~g}^{-1}$ ) for HA [40-45]. Therefore, it may not be appropriate to use the DLM to implement the humic ion-binding models of Tipping and coworkers in PHREEQC. Instead, the constant capacitance model (CCM) was used. The $\mathrm{CCM}$ is a very simple electrostatic model in which the capacitance $\left(C\right.$, in $\left.F m^{-2}\right)$ is an adjustable parameter that varies with the IS [46]. Specifically, the CCM employs a linear relationship between the surface charge density $\left(\sigma_{0}\right.$, in $\left.\mathrm{C} \mathrm{m}^{-2}\right)$ and the surface potential $\left(\boldsymbol{\Psi}_{0}\right.$, in $\mathrm{V}), \sigma_{0}=C \times \Psi_{0}$.

However, the CCM is not defined in PHREEQC and had therefore to be implemented in PHREEQC-MODEL VI. To do this, we modified the TLM (triple layer model) in PHREEQC to only consider the capacitance of the 1-plane, $C_{1}\left(F \mathrm{~m}^{-2}\right)$. In the TLM model, the capacitance of the 2-plane $C_{2}$ was set to a very large value $\left(C_{2} \approx \infty\right)$ to be annulled. In the resulting model (i.e. a basic Stern model), if the surface area $A\left(\mathrm{~m}^{2} \mathrm{~g}^{-1}\right)$ is multiplied by a large factor $X\left(\right.$ e.g. $\left.X=10^{7}\right)$, the double layer is suppressed. The new surface area is $A^{\prime}=$ $(\mathrm{A} \times \mathrm{X})$ and the surface charge density at the 0 -plane is $\sigma_{0}{ }^{\prime}=\left(\sigma_{0} / \mathrm{X}\right)=\left(\mathrm{C}_{1} \times \mathrm{X}\right) \times \Psi_{0}\left(\mathrm{C} \mathrm{m}^{-2}\right)$. The charge at the 0 -plane (in eq $g^{-1}$ ) is $Z_{0}=A \times \sigma_{0} / F=A^{\prime} \times \sigma_{0}{ }^{\prime} / F$, where $F$ is Faraday's constant (in 
C mol $\left.{ }^{-1}\right)$. At the 0 -plane, then: $Z_{0}=A^{\prime} \times\left(C_{1} / X\right) \times \Psi_{0} / F$. By setting the new capacitance in PHREEQC as $C_{1}{ }^{\prime}=C_{1} / X$, the charge-potential relationship remains unchanged for the 0 plane, whereas the diffuse layer is suppressed by the high A' value. This approach results in the CCM.

In Model VI [37], the electrostatic term $\mathrm{F} \times \Psi /(\mathrm{R} \times \mathrm{T})$ is replaced by $2 \times \mathrm{P} \times \mathrm{Z} \times \log \mathrm{I}$, where $\mathrm{I}$ is the IS (mol L-1) and $\mathrm{P}$ is an adjustable parameter (generally $-400<\mathrm{P}<-100$ ) that only depends on the humic substance considered (e.g. composition, origin). Then, the chargepotential relationship is: $Z=F \times(2 \times R \times T \times P \times l o g ~ I)^{-1} \times \Psi$. In fact, the latter $Z-\Psi$ relationship is similar to the CCM in which the capacitance $C_{1}=F^{2} \times(2 \times R \times T \times P \times A \times l o g ~ I)^{-1}$. As the parameter $P$ is negative, $C_{1}$ is a function of $-1 / \log I$. The capacitance $C_{1}$ thus increases with I (IS). According to the molar mass and the radius of $\mathrm{HA}\left(15000 \mathrm{~g} \mathrm{~mol}^{-1} ; 1.72 \mathrm{~nm}\right)$ in Model VI, the surface area of $\mathrm{HA}\left(\mathrm{A}_{\mathrm{HA}}\right)$ is $1500 \mathrm{~m}^{2} \mathrm{~g}^{-1}$. $\mathrm{C}_{1}$ can therefore vary from $0.6 \mathrm{~F} \mathrm{~m}^{-2}$ (for $\mathrm{P}=-400, \mathrm{I}=$ $10^{-4} \mathrm{M}$ ) to $9.4 \mathrm{~F} \mathrm{~m}^{-2}$ (for $\mathrm{P}=-100, \mathrm{I}=10^{-1} \mathrm{M}$ ), within the same order of magnitude as the minerals [46].

Ion accumulation in the vicinity of HA is calculated with a Donnan model. The Donnan volume $\left(V_{D}\right)$ is the surface area multiplied by the thickness of the accumulation layer. This thickness is approximated by the Debye-Hückel parameter $\kappa$, where $\kappa^{-1}=\left(3.29 \times 10^{9} \times I^{1 / 2}\right)^{-1}$. Because working with the CCM in PHREEQC/Model VI requires an unrealistic surface area value, a thickness $L=\kappa^{-1} / X$ must be used in PHREEQC/Model VI to keep a realistic $V_{D}$ value. For $H A: V_{D}=A_{H A} \times \kappa^{-1}=A^{\prime} \times L$. Here, $A=10^{7} \mathrm{~m}^{2} \mathrm{~g}^{-1}$, therefore $L=1.5 \times 10^{-4} \times$ $\left(3.29 \times 10^{9} \times \mathrm{I}^{1 / 2}\right)^{-1}=1.44 \times 10^{-12} \mathrm{~m}$ for $\mathrm{I}=10^{-3} \mathrm{M}$. $\mathrm{V}_{\mathrm{D}}$ is therefore equal to $1.44 \times 10^{-5} \mathrm{~m}^{3} \mathrm{~g}^{-1}$ (or 14.4 $\left.\mathrm{L} \mathrm{kg}^{-1}\right) . V_{D}$ is within the same magnitude order as $V_{D}$ in NICA-Donnan, which varied from 1 to $80 \mathrm{~L} \mathrm{~kg}^{-1}$ [47]. Table 1 summarizes the parameters defined for the CCM model in the modified PHREEQC-Model VI.

\subsubsection{Fitting the binding parameters}

The PHREEQC-Model VI binding parameters were fitted using the program PHREEPLOT [44] using the experimental datasets recovered from the titrations and isotherm 
experiments. The 84 types of sites defined in PHREEQC-Model VI as well as the 84 complexation reactions with $\mathrm{H}^{+}$were added in the "minteq.v4" database. Humic acids were defined as SOLUTION_MASTER_SPECIES, SOLUTION_SPECIES and PHASES. The modeling procedure was designed to determine: (i) the intrinsic proton dissociation constants, the distribution terms and the abundance $(n)$ of the $A, B$ and $S$ type sites (Leonardite and S(-II)-Leonardite), and (ii) the specific binding parameters of the thiol groups for As(III), (Leonardite, S(-II)-Leonardite). The binding parameters were determined for Mono and Tri models, respectively. However, this set of parameters was large and had to be decreased to better constrain the model. The abundance parameter for the phenolic groups $\left(n_{B}\right)$ was set to half of the abundance parameter $\left(n_{A}\right)$ for the carboxylic groups, as proposed by Tipping [37]. This assumption is in agreement with the proportion determined in the literature [48] and in several ion-OM binding models $[49,50]$. The parameter $\mathrm{n}_{\mathrm{S}}$ was considered to be minor compared to $n_{A}$ and $n_{B}$ and regards to the total concentration of $S$ $\left(\mathrm{S}_{\text {tot }}\right)$ in humic acids $\left(0.76 \%\right.$ of $\mathrm{S}$ in IHSS Leonardite). Only a part of $\mathrm{S}_{\text {tot }}$ occurs as thiol sites, which were supposed to be the more reactive groups regards to As(III) binding. The concentration of thiol groups, namely $n_{S}$, could be estimated from $S_{\text {tot }}$ and from the \% thiol, as :

$$
\mathrm{n}_{\mathrm{S}}=\text { thiol } \% * \mathrm{~S}_{\text {tot }}
$$

If the thiol $\%$ was not determined for the used Leonardite $\mathrm{HA}$, a range of thiol \% was available in the literature for various humic acids [51-57], mainly determined from XAS records. This range varied from 10 to $50 \%$ of $S_{\text {tot }}$ as thiol groups. Therefore, to estimate the $\mathrm{H}^{+}$dissociation constant and binding parameters of $\mathrm{As}(\mathrm{III})$ with leonardite, 5 fits were performed on this range, namely with $n_{S}=10,20,30,40$ and $50 \%{ }^{*} S_{\text {tot. }}$. For this 5 fits, $n_{S}$ parameter for Leonardite and $\mathrm{n}_{\mathrm{s}}$ ' for S(-II)-Leonardite were calculated as:

$$
\begin{aligned}
& \mathrm{n}_{\mathrm{S}}=\text { thiol \%* } \mathrm{S}_{\text {tot }}(\text { Leonardite }) \\
& \mathrm{n}_{\mathrm{S}^{\prime}}=\mathrm{S}_{\mathrm{tot}}(\mathrm{S}(-\mathrm{II}) \text {-Leonardite })-\mathrm{S}_{\mathrm{tot}}(\text { Leonardite })+\mathrm{n}_{\mathrm{S}} \\
& \mathrm{n}_{\mathrm{S}^{\prime}}=\mathrm{S}_{\mathrm{tot}}\left(\mathrm{S}(-\mathrm{II}) \text {-Leonardite) }-\mathrm{S}_{\mathrm{tot}}(\text { Leonardite })+\text { thiol \%* } \mathrm{S}_{\mathrm{tot}}(\text { Leonardite) (Eq. 8) }\right.
\end{aligned}
$$


The binding parameter $\log \mathrm{K}_{\mathrm{Ms}}$ was fitted from isotherm datasets using the combination of PHREEPLOT/PHREEQC-Model VI for the various thiol $\%\left(n_{S}=10,20,30,40\right.$ or $50 \%$ * $\left.S_{\text {tot }}\right)$. In the model's hypothesis, no strong bidentates and tridentates are possible, and the strong site parameter of the thiol groups, $\Delta \mathrm{LK}_{2}$ did not need to be fitted. However, we had to attribute a value to the $\Delta \mathrm{LK}_{1}$ of thiol $\left(\Delta \mathrm{LK}_{1 \mathrm{~S}}\right)$. We chose to fix $\Delta \mathrm{LK}_{1 \mathrm{~S}}$ to the $\Delta \mathrm{LK}_{1}$ of the strong site used by Tipping [37]: $\Delta \mathrm{LK}_{1 \mathrm{~B}}=\Delta \mathrm{LK}_{1 \mathrm{~S}}=0.8$. Arsenic(III) log $\mathrm{K}_{\mathrm{MS}}$ was optimized using the weighted sum of squares of the residuals, RMSE (Root Mean Square Error). The stability constants of the four thiol sites - log $\mathrm{K}$ (monodentates or tridentates) - defined in PHREEQCModel VI were calculated from log $\mathrm{K}_{\mathrm{MS}}$ and $\Delta \mathrm{LK}_{1 \mathrm{~B}}$ (see supporting information SI 5).

\subsubsection{Dataset from the literature}

Seven literature datasets were used to compare both tested models $[17,18,20,22,23,25,58]$. The abundance of the thiol sites, $n_{s}$, had to be determined for each dataset. Manceau et al. (2012) determined, from XANES fitting, that $23.6 \%$ of $S$ is as exocyclic form in SRHA. We supposed here that this \% corresponds to the thiol \%. For Hoffmann et al. [25], the thiol concentrations were determined by the authors. However, since no XANES data were available for PAHA and AHA, modeling calculations were thus performed on a thiol \% range $\left(n_{S}=10,20,30,40\right.$ and $\left.50 \%{ }^{*} S_{\text {tot }}\right)$ with $S_{\text {tot }}$ equal to $2.33 \%$, $4.2 \%$ and $0.54 \%$ for PAHA [59], AHA [60] and SRHA (value from IHSS), respectively.

\section{Results}

\subsection{S(-II) grafting and titration}

After $\mathrm{S}(-\mathrm{II})$ addition, the concentration of $[\mathrm{S}(-\mathrm{II})]$ outside of the dialysis membrane decreased and reached 0 after about 20h (supporting information SI 6). For the titration and isotherm experiments, the S(-II)-Leonardite stock solution was sampled after $24 \mathrm{~h}$ of grafting and was used immediately.

The titrations of Leonardite and S(-II)-Leonardite for two IS are plotted in Fig. 1. The global charge decreased with increasing $\mathrm{pH}$. At basic $\mathrm{pH}$, the charge $\mathrm{Q}$ was more negative for $\mathrm{S}(-\mathrm{II})$-Leonardite than for Leonardite $\left(\right.$ at $\mathrm{pH}=10, \mathrm{Q}\left(\mathrm{S}(-\mathrm{II})\right.$-Leonardite) $=-4.32 \mathrm{meq} \mathrm{g}^{-1}$ 
versus $Q($ Leonardite $\left.)=-2.98 \mathrm{meq}^{-1}\right)$. This difference in charge, $\mathrm{Q}(\mathrm{S}(-\mathrm{II})$-Leonardite $)$ $\mathrm{Q}($ Leonardite $)=-4.32+2.98=-1.34 \mathrm{meq}^{-1}$, corresponds to the charge developed by the thiol groups added to the Leonardite during the grafting.

\subsection{Adsorption isotherms}

From the $A s(I I I)$ and $A s(V)$ concentrations measured in the ultrafiltrate, it can be observed that no oxidation occurred in any of the samples. Fig. 2: Ex presents the adsorption isotherms of $\mathrm{As}(\mathrm{III})$ by Leonardite and $\mathrm{S}(-\mathrm{II})$-Leonardite $(\log [\mathrm{As}(\mathrm{III})-\mathrm{HA}]$ relative to log $[\mathrm{As}(\mathrm{III})])$. No plateau was reached for either HA. The percentage of As(III) bound to the Leonardite was below $5 \%$, and between 5 and $15 \%$ for the S(-II)-Leonardite. The adsorption of As(III) was clearly stronger for S(-II)-Leonardite than for Leonardite. The highest concentration of bound As to S(-II)-Leonardite confirmed that the addition of thiols to HA increased its binding capacity with regards to As(III).

\subsection{H-HA model}

To determine the quality of the fit between the measured and modeled data using PHREEQC/Model VI, RMSE values were calculated according to RMSE = $\sqrt{\text { mean }\left((\log \mu(\exp )-\log \mu(\mathrm{cal}))^{2}\right.}$, with $\log \mu(\exp )$ and $\log \mu(\mathrm{cal})$ representing the logarithm of the charge (or concentration) of the experimental data and modeled data, respectively. For the titration dataset, the RMSE was 0.03 for all calculated $n_{S}$, indicating that the fitted $\mathrm{H}^{+}$ binding parameters were able to reproduce the experimental dataset. The protonation/deprotonation parameters for the carboxylic and phenolic groups are listed in Table 2 for the various thiol \%. The protonation/deprotonation parameters were in the range of the standard deviation $( \pm)$ of the model. They were within the same range as the parameters given by Tipping (1998) for Model VI, except for $\mathrm{n}_{\mathrm{A}}$ and $\mathrm{pK} \mathrm{K}_{\mathrm{B}}$, the reasons for which are discussed below in the discussion section. 


\subsection{As-HA model}

Using the protonation/deprotonation constants of the 12 (carboxylic, phenolic and thiol) binding sites of HA for each thiol abundance, the binding parameter for the thiol groups ( $\log \mathrm{K}_{\mathrm{MS}}$ ) was determined using the dataset from the Leonardite and S(-II)-Leonardite isotherm experiment. The log $\mathrm{K}_{\mathrm{MS}}$ calculated with the Mono model, which hypothesizes the complexation of $\mathrm{As}$ (III) by HA through monodentate complexes only, was equal to $2.93\left(\mathrm{n}_{\mathrm{S}}=\right.$ $\left.10 \%{ }^{*} S_{\text {tot }}\right), 2.92\left(n_{S}=20\right.$ and $\left.30 \%{ }^{*} S_{\text {tot }}\right)$ and $2.91\left(n_{S}=40\right.$ and $50 \%$ * $\left.S_{\text {tot }}\right)$ whereas it varied from $2.93\left(n_{S}=10 \%{ }^{*} S_{\text {tot }}\right)$ to $2.12\left(n_{S}=50 \%{ }^{*} S_{\text {tot }}\right)$ for the Tri model, in which complexation is assumed to occur through the tridendate complexes. The simulation of As(III) binding by Leonardite and S(-II)-Leonardite with the Mono and Tri models is displayed in Fig. 2: Exa. For the Mono model, the binding parameter, $\log \mathrm{K}_{\mathrm{MS}}$, did not vary significantly with the thiol $\%$. However, the corresponding RMSE decreased from 0.72 to 0.33 with the increasing $n_{S}$ (Table 4). By contrast, for the Tri model, log $\mathrm{K}_{\mathrm{MS}}$ increased strongly with the decreasing thiol $\%, \log \mathrm{K}_{\mathrm{MS}}=2.93$ to 2.12 . It is important to note that these differences were multiplied by a factor of 3 for the corresponding $\log K$ (see part 2.4 ), which thus varied from $2.12^{*} 3=6.36$ to $3 * 2.93=8.79$. Regards to the smallest RMSE, for all the following calculations, log $K_{M S}$ was fixed at 2.91 and 2.12 for the Mono and Tri models, respectively. The modeling performed with both the Mono and Tri models was very similar, as demonstrated by the RMSE values of 0.33 and 0.27 , respectively. The standard deviations calculated for the log $\mathrm{K}_{\mathrm{MS}}$ values were small (0.03 and 0.02 for the Mono and Tri models, respectively). Therefore, these two simulations alone could not be used to validate either one of the models in particular. To further validate the modeling approach, the fitted binding parameters therefore had to be tested using other experimental datasets.

\subsection{Simulations with the Mono and Tri models}

The RMSE fits were averaged and weighted by all available data (Table 3) to compare Mono and Tri models. 
PAHA. Three studies used this HA [the present study, 17-18]. The first used dataset was produced in the present study and corresponded to the As(III) adsorption isotherm on purified Aldrich humic acid (PAHA) (Fig. 2a). Between 7 and $16 \%$ of As(III) were bound to PAHA in the performed experiments. The present produced datasets were better fitted with the Tri model than with the Mono model (mean RMSE $=0.86$ and 0.62 for the Mono and Tri models, respectively). By contrast, both other datasets $[17,18]$ were less simulated (mean RMSE $=0.73$ and 0.53 against 1.24 and 0.82 for the Mono and Tri models, respectively) The weighted RMSE was lower for the Mono than for the Tri models (RMSE $=0.67$ and 0.90 for the Mono and Tri models, respectively) (Table 3 and SI2 a and b).

AHA. Several studies used this $\mathrm{HA}[17,22,23,58]$ at various $\mathrm{pH}$ and $\mathrm{HA}$ concentrations. Note that this humic acid was not purified with the IHSS protocol and contained probably humin, humic and fulvic acids and impurities (silica, metals, etc.). The experimental datasets from Kappeler [58] and Liu and Cai [22] at pH 5.2 were better fitted with the Tri than the Mono models (RMSE mean $=0.4,0.3$ and 0.51 and 0.52 , respectively) (Fig. 2c and Table 3). However, Liu and Cai [22] datasets at pH 7 and 9, Fakour and Lin [23] and Thanabalasingam and Pickering [17] were better fitted with the Mono than with the Tri models (Table 3 and SI 2d, f, g, h, i). For all datasets, the lower weighted RMSE was obtained for the Mono model (Table 3). The datasets at high $\mathrm{pH}$ were lesser fitted by both models which was probably account for the presence of $\mathrm{H}_{2} \mathrm{AsO}_{3}{ }^{-}$specie that was bound to HA with a mechanism not described in both models.

SRHA. Only two datasets used this HA $[20,58]$. The used thiol \% of SRHA was determined as $n_{S}=23.6 \%$ * $S_{\text {tot }}[56]$. Regards to the experimental $\mathrm{pH}$ range, the fitting calculations used only 3 and 2 data points for Kappeler [58] and Lenoble et al. [20] datasets, respectively. The best fits were obtained with the Tri model (Table 3, Fig. 2d and SI2j). However, regards to the small number of data, RMSE should be considered carefully (see Discussion section).

Elliot Soil HA and Peat. For both datasets, thiols were grafted to HA and their \% were estimated using XRF spectroscopy. The Hoffmann et al. [25] HA dataset was lesser 
reproduced by the Mono than the Tri models (Fig. 2: Exe and Table 3) (RMSE $=0.74$ for the Mono model versus 0.19 for the Tri model). By contrast, neither the Mono nor the Tri model reproduced the peat dataset of Hoffmann et al. [25], over the entire thiol \% range (Fig. 2: Exf, Table 3). More precisely, the Tri model could simulate the experimental dataset at low thiol $\%$, but the Mono model better simulated the dataset at high thiol \%. The weighted RMSE calculated for both datasets was better for the Tri than for the Mono model. However, the spectroscopic data obtained by Hoffman et al. [25] clearly allowed to reject the Tri model, since only one S was determined in the vicinity of the As(III) [25].

Based on the weighted RMSE calculated for all datasets, it appears that the Mono model better simulated the experimental datasets than the Tri model, notably regards to the data from PAHA and AHA (Table 3). Moreover, as specified before, for the datasets at $\mathrm{pH}>7$ ([22] at $\mathrm{pH} 7$ and 9.3, [23]) the potential presence of $\mathrm{H}_{2} \mathrm{AsO}_{3}{ }^{-}$species decreased the fit quality. Using the datasets for $A H A$ and $P A H A$ at $p H<7$, namely without $\mathrm{H}_{2} \mathrm{AsO}_{3}{ }^{-}$, the weighted RMSE decreased to 0.60 and 0.75 for Mono and Tri models, respectively (Table 3) indicating that the Mono model simulated more datasets than the Tri model. Note that the high RMSE were due to the large range of thiol \% used for AHA and PAHA $\left(n_{S}=10-50 \%\right.$ * $\left.\mathrm{S}_{\text {tot }}\right)$.

\section{Discussion}

\subsection{H-HA parameters}

The protonation/deprotonation parameters for the A, B and S sites are presented and compared to Tipping's parameters [37] for Model VI (Table 2). The variation in the carboxylic and phenolic abundances might be explained by the implementation of thiol groups $\left(\mathrm{n}_{\mathrm{S}}\right)$. For a same total abundance of site (dependent only on the type of humic substance), three different abundances $\left(n_{A}, n_{B}\right.$ and $\left.n_{S}\right)$ are defined here versus two abundances $\left(n_{A}\right.$ and $\left.n_{B}\right)$ in Model VI. Fig. 1 showed that the HA titrations performed in this study are within the range of the HA titration values compiled by Milne et al. [61]; notably, the obtained $\mathrm{pK}_{\mathrm{A}}$ and $\Delta \mathrm{pK}_{\mathrm{A}}$ are close to those of Tipping's parameters [37]. The most noticeable difference occurred for $\mathrm{pK}_{\mathrm{B}}$ 
which was explained by the fact that in Model VI, the thiol and phenol groups were grouped together and considered as site B. Data from the literature showed that the $\mathrm{pK}$ of the phenol ligands seems to depend on the carbon radical to which the hydroxyl $(\mathrm{OH})$ is bound. For example, the pK of hydroxybenzene, $\left(\mathrm{OH}^{-}\right.$bound to one benzoic cycle) is 9.98 (at $25^{\circ} \mathrm{C}$ and IS $\left.=0 \mathrm{~mol} \mathrm{~L}^{-1}\right)$ versus 7.21 for nitrophenol $(\mathrm{OH}$ bound to one benzoic cycle, which is itself bound to $\left.\mathrm{NO}_{2}\right)\left(\right.$ at $25^{\circ} \mathrm{C}$ and $\left.\mathrm{IS}=0 \mathrm{~mol} \mathrm{~L}^{-1}\right)$. As the molecular structure of $\mathrm{OM}$ is complex and heterogeneous, the form/structure of the carbon radical of phenol cannot be identified. However, the fitted $\mathrm{pK}_{\mathrm{B}}$ of 7.11 obtained in this study was consistent with the $\mathrm{pK}_{\mathrm{A}}$ of phenol.

The $\mathrm{H}^{+}$dissociation constant for the thiol groups, $\mathrm{pK}_{\mathrm{S}}=5.82 \pm 0.05$, was lower than $\mathrm{pK}_{\mathrm{B}}$, suggesting that thiol groups are more deprotonated at acidic $\mathrm{pH}$ than phenolic groups. For a simple organic ligand (aliphatic or aromatic) containing thiol groups, the pK varied from 5.2 to 13.24 (Fig. 3). This $\mathrm{pK}_{\mathrm{A}}$ range correlates with the molecular weight of the molecules: $\mathrm{pK}_{\mathrm{A}}$ decreases with increasing molecular weights (Fig. 3). Moreover, for aromatic molecules containing one thiobenzene, the increasing molecular weight of the radical associated with the aromatic ring is correlated with the decreasing $\mathrm{pK}_{\mathrm{A}}$. Based on this dataset, the low $\mathrm{pK}_{\mathrm{S}}$ (5.82) obtained for the deprotonation of the thiol sites can therefore be justified by the high molecular weight and aromaticity of $\mathrm{HA}$ (Fig. 3). The distribution term of $\mathrm{pK}_{\mathrm{s}}, \Delta \mathrm{pK}_{\mathrm{s}}$, was high $(6.12 \pm 0.12)$, suggesting that the thiol pK were distributed over a large pK range. Humic acids are not only macromolecular but also supramolecular moieties [62], i.e. not only formed with high weight aromatic molecules but also lower weight molecules. The correlation between pK for the thiol group and the molecular weight of thiol-containing organic molecules might therefore explain this high distribution $\left(\Delta \mathrm{pK}_{\mathrm{S}}\right)$. Several simulations were performed to test the influence of $\Delta \mathrm{pK}_{\mathrm{S}}$ on the fitting of the As(III)-HA binding parameters. Variations in $\Delta \mathrm{pK}_{\mathrm{S}}$ did not produce any variation for the As(III) concentrations bound to HA (supporting information SI 8). 


\subsection{As(III)-HA binding parameters}

There is no consensus regarding the mechanisms involved in the binding of $\mathrm{As}$ (III) by HA. Buschmann et al. and Lenoble et al. $[19,20]$ proposed that this binding occurs through the complexation of As(III) by carboxylic and phenolic groups. These functional groups are the most abundant in OM and they are able to complex many cations such as Fe(II, III), REE, Al, Mg, etc. [50,63-65]. However, the direct complexation of As(III) species by HA carboxylic groups has not been supported so far by any spectroscopic data. At any rate, the log $\mathrm{K}$ of As(III) binding to simple organic ligands is low - As(III)-catechol with $\log K=-6.89$ and As(III)pyrogallol with $\log \mathrm{K}=-6.32$ [66], indicating that this complexation, if any, should be of minor importance. By contrast, recent spectroscopic studies suggested two new binding mechanisms. The first one consists of an indirect mechanism in which As(III) is bound to OM via Fe $[15,18,19,22,67,68]$. The second consists of a direct mechanism in which As(III) is bound to OM via thiol functional groups $[39,69]$. Arsenic(III) has high affinity for S containingligands. The stoechiometry of the formed As-thiol organic molecules are either 1:1 (i.e. thiol in peat and HA [25]) or 1:3 (i.e. cystein [30]) depending on the ligand involved. In this study, two models were designed to test the reality of these complexes, i.e. the monodentate $(1: 1)$ model, the so-called Mono model, and the tridentate (1:3) model, the Tri model. Simulations of published datasets with the binding parameters established using the experimental data of this study demonstrated that the Mono model well reproduced more datasets than the Tri model (weighted RMSE $=0.86$ and 1.22 for the Mono and Tri models, respectively) . Considering the datasets of PAHA and $\mathrm{AHA}$ without $\mathrm{H}_{2} \mathrm{AsO}_{3}{ }^{-}$species, the mean RMSE was lower with the Mono than the Tri model. The Mono model is in accordance with the binding mechanisms proposed by Hoffmann et al. [25], i.e. the formation of monodentate complexes. Hoffmann et al.'s spectroscopic study [25] demonstrated that only one S is located in the vicinity of $\mathrm{As}(\mathrm{III})$ in their $\mathrm{HA}$ sample $(0.5<\mathrm{CN}$ (coordination number) $<1.5$ at $2.29-2.34 \AA$ ). The fact that neither the Mono model nor the Tri model was successful in fitting these experimental data [25] could be explained by the experimental conditions used by the authors. In order to meet the requirement for the spectroscopic analyses, high As(III) and HA 
concentrations had to be used in the experiments. These high amounts of As(III) could promote the formation of arsenite polymers. This hypothesis is supported by the presence of As in the vicinity of the bound As(III) in the EXAFS fitting of HA data by Hoffmann et al. [25] $(0.3<\mathrm{CN}<0.5$ at $2.63-2.67 \AA)$. This model, which only considered As(III), therefore overestimated the bound As(III) concentrations. The same overestimation was obtained for Warwick et al.'s dataset [18]. The experimental conditions of this dataset $([\mathrm{As}(\mathrm{III})]=2-42 \mathrm{mg}$ $\mathrm{L}^{-1}$ and $\left.[\mathrm{HA}]=1.5 \mathrm{~g} \mathrm{~L}^{-1}\right)$ were within the same range as those of Hoffmann et al. [25] ([As(III)] $=4.1 \mathrm{mg} \mathrm{L}^{-1}$ and [peat] $=4.5 \mathrm{~g} \mathrm{~L}^{-1}$ ) and it is likely that $\mathrm{As}(\mathrm{III})$ polymers were formed during these experiments. Moreover, the sorption isotherm of Warwick et al. [18] exhibited two sorption increase/decrease steps (see supporting information SI 2c), a feature that could not be explained. The differences between the experimental and modeled data for the peat dataset of Hoffmann et al. [25] can be explained by the nature of the peat used, as it is a specific OM formed in very specific conditions and this could thereby influence its composition and surface reactivity. The Mono model also failed to reproduce SRHA datasets $[20,58]$. Since the occurrence of $\mathrm{H}_{2} \mathrm{AsO}_{3}{ }^{-}$was expected for most data, only five points of both datasets could be used for fitting. The RMSE depended on the number of extrapolated points. For large datasets, the RMSE is expected to be lower than for small datasets. Moreover, a high discrepancy was observed between Kappeler [58] and Lenoble et al. [20] datasets. Lenoble et al. [20] showed that between 30 to $80 \%$ of As(III) was bound to SRHA versus 0.11 to $23.9 \%$ for Kappeler [58] for equivalent experimental conditions (at $\mathrm{pH}=8.4$, $\mathrm{DOC}=50 \mathrm{mg} \mathrm{L}^{-1},[\mathrm{As}(\mathrm{III})]_{\mathrm{tot}}=0.134 \mu \mathrm{mol} \mathrm{L}^{-1}, \mathrm{As}(\mathrm{III})$ bound $=8.87 \%$ and $\mathrm{pH}=8, \mathrm{DOC}=15$ $\mathrm{mg} \mathrm{L}^{-1}$ and $[\mathrm{As}(\mathrm{III})]_{\mathrm{tot}}=0.16 \mu \mathrm{mol} \mathrm{L}^{-1}, \mathrm{As}(\mathrm{III})$ bound $=38 \%$, respectively). So far, we have no explanations for these observed differences. The RMSE were high for both Mono and Tri models. These RMSE corresponded to the average of the RMSE calculated for the 5 tested $n_{S}$ in the calculation of which $S_{\text {tot }}$ had the same values for each PAHA and each AHA samples, $(\% \mathrm{~S}=2.33 \%$ and $4.2 \%$ for PAHA and AHA, respectively). However, considering the date of the various published studies, HA were probably provided from different lots. Moreover, for PAHA, the purification had probably modified $S_{\text {tot }}$ and thiol $\%$ in the HA sample. 
Therefore, modeling calculations should only be considered as estimations and they had to be improved with the true $\mathrm{S}_{\text {tot }}$ and thiol \%.

The As(III)-thiol HA binding parameter $\log \mathrm{K}_{\mathrm{MS}}$ is equal to $2.91 \pm 0.04$. Log $\mathrm{K}_{\mathrm{MS}}$ was determined for protonated HA (see Eq. 4), in contrast to cation binding in PREEQC-Model VI and Model VI. For deprotonated species, $\log \mathrm{K}_{\mathrm{MS}}$ is equal to $=-5.38$, which is very low compared to the $\log \mathrm{K}_{\mathrm{MA}}$ and $\log \mathrm{K}_{\mathrm{MB}}$ of cations $\left(\log \mathrm{K}_{\mathrm{MA}}(\mathrm{Ba})=-0.2<\log \mathrm{K}_{\mathrm{MA}}\right.$ (Model $\left.\mathrm{VI}\right)<$ $\left.\log \mathrm{K}_{\mathrm{MA}}(\mathrm{Dy})=2.9\right)$. This indicates that the capacity of HA to bind $\mathrm{As}(\mathrm{III})$ is much lower than the capacity of HA to bind cations. This is not surprising in terms of the global negative charge of $\mathrm{HA}$ and the neutral charge of $\mathrm{As}(\mathrm{III})$ which had to lose one $\mathrm{OH}$ in order to be bound to the negative charged-thiol group in HA.

In figure 4 were plotted the $\log \beta$ relative to the number of coordinated thiols in the complexes formed between As(III) and thiol-containing organic molecules. It is important to note that Rey et al.'s log $\beta$ [29] values are much higher than the $\log \beta$ values determined by other workers, as previously noted [30]. Log $\beta$ increased with the increasing number of coordinated thiols. The binding of As(III) to dithiol molecules (e.g. dimercaptosuccinic acid DMSA) leads to the formation of a ring stabilizing the complex. Few data for monodentate $1: 1$ complexes between $\mathrm{As}(\mathrm{III})$ and thiol-containing molecules are available in the literature. Thiol groups are strongly reactive regards to $\mathrm{As}(\mathrm{III})$ and $\mathrm{As}(\mathrm{III})$ is therefore often bound to 2 or 3 thiols, as bi- or tridentate complexes. The $\log \mathrm{K}_{\mathrm{MS}}$ (here, $\log \mathrm{K}_{\mathrm{MS}}=\log \mathrm{K}$ ) of 2.91 extrapolated for the Mono model was within the log $\beta$ range of the $1: 1$ complexes (Fig. 4). Moreover, for aryl arsinous acid $\left(\operatorname{ArAs}\left(\mathrm{CH}_{3}\right) \mathrm{OH}\right)$, in which only $\mathrm{OH}$ is available for binding, Liang and Drueckhammer [70] determined a $\log \beta$ of 2.80 with mercaptoethane, which was close to $\log \mathrm{K}$ determined in this work. The extrapolated $\log \mathrm{K}_{\mathrm{MS}}$ confirmed thereby the low affinity of $\mathrm{As}(\mathrm{III})$ for $\mathrm{HA}$.

For, the Tri model, extrapolated $\log \mathrm{K}_{\mathrm{MS}}$ was 2.02 and corresponded to $\log \mathrm{k} \approx 3{ }^{*} \log \mathrm{K}_{\mathrm{MS}}=$ 6.06. This calculated log $\mathrm{k}$ was in the range of the $\log \beta$ of the 3 coordinated thiol-As (III) complexes. Among this group, the binding mechanism can occur through 1:3, 1:2, 1:1 complexes. The Tri model corresponded, here, to the formation of tridentate 1:1 complexes. 
The $\log \beta$ of the tridentate $1: 1$ complexes of the group of the 3 coordinated thiols were lower than those of the Tri model (Fig. 4Error! Reference source not found.).

If the formation of tridentates is efficient for $\mathrm{As}$ (III) binding by peptides, proteins, organic ligands or thiol-resin $[26,28-31,33,39]$, the present results did not provide evidence that in $\mathrm{HA}$, the formation of tridentates is promoted. In organic ligand or thiol-resin, there was a high density of thiol groups compared to HA, in which phenolic and carboxylic groups predominate $\left(n_{A}>12 \times n_{S}\right.$ in the present study). Moreover, in Hoffmann et al. [25], although the HA samples were grafted with thiols, only monodentates were formed, as evidenced by the spectroscopic analyses. Thus, the thiol concentrations are not the only controlling factor for monodentates or tridentates formation. Numerous organic ligands formed 1:3 (e.g. cysteine, glutathione) or 1:2 complexes (e.g. Sp1-zf2 f565-595 protein) with As(III) (Fig. 4). Many of them are aliphatic and carry two or more thiol sites that are thus close to each other (e.g. dithiothreitol, dimercaptosuccinic acid). Spuches et al. [30] provided evidence that entropic factors are important in constraining the stability of the complex formed between As(III) proteins. Therefore proteins, in which the vicinity of the cysteine residue (i.e. the thiol groups) are conformably constrained (entropic advantage) and favorably positioned, are expected to form a high denticity complex $(\max 3)$ with As(III). Moreover, some peptides and proteins are flexible in solution, which allows As(III) to bind several thiol groups despite the distances between the thiol sites, subsequently modifying the geometry of the molecules [28]. In contrast to what occurs with peptides and proteins, HA are complex moieties that are strongly rigidified by the presence of aromatic rings. This rigidity combined with the low thiol density and subsequent high distances between the thiol groups prevent the formation of tridendate complexes with As(III).

\subsection{Implications of the direct binding mechanism evidenced}

The present study further demonstrated the ability of HA to directly bind As(III) via their thiol functional groups. However, the calculated binding parameters are low, suggesting a global weak affinity of As(III) for HA even though this affinity could be high for a few specific 
sites as suggested by the high value of the distribution term, $\Delta \mathrm{pK}_{\mathrm{s}}$. The binding of As(III) by HA will therefore probably play a minor role in the fate of As in organic-rich waters. However, if the available database indicates that the amount of $\mathrm{As}(\mathrm{III})$ bound to HA should be low in most cases, this amount will depend on the abundance of the thiol functional groups in HA. Since thiol \% were not determined for the whole datasets, the thiol concentration had to be tested within the range expected from spectroscopic analyses $\left(n_{s}=10,20,30,40\right.$ and $50 \%$ * $S_{\text {tot). }}$. The obtained RMSE decreased with the increasing thiol concentrations, which provided evidence of a strong dependency between the amounts of bound As(III) and the thiol groups. The thiol abundance will be the major controlling factor with regards to the direct binding of As(III) to HA. Therefore, the composition and structure of HA will influence the amount of As on the surface of the humic colloids or particles. The sulfur concentrations in organic matter, especially in humic substances, vary a lot; for example, among the humic substances sold by IHSS, the sulfur concentrations vary from $0.36 \%$ (Waskish Peat reference HA) to $3.03 \%$ (Pony Lake fulvic acid). The first HA is sourced in deep, very poorly drained organic soils and consist of decomposed bogs, whereas Pony Lake fulvic acid comes from a saline coastal pond from Antartica and is composed of purely microbially-sourced fulvic acid. This microbial composition should explain the high concentration of sulfur found in this fulvic acid. Moreover, the only $\mathrm{S}_{\text {tot }}$ amount was not sufficient to determine the thiol concentrations in humic substances. The concentrations of thiol groups varied from from 1 to $46.9 \%$ [51-57]. To better understand the binding of As(III) to thiol groups, it is therefore absolutly necessary to determine thiol concentrations. If XAS techniques allow to estimate exocyclic $S$ and thiol concentrations. its sensibility is low and this technique requires high concentrations of thiol [53]. Recently, Rao et al. [53],proposed to a new titration methoded based on the used of ThioGlo-1 as thiol groups complexing agent [53]. These type of method had to be developed to systematically determine thiol concentrations and better estimated the $\mathrm{As}(\mathrm{III})$ amount bound to organic matter.

Since thiol groups are good potential binding sites for As(III), reduced peatland environments (in the absence of sulfurs that can precipitate As) with potentially high (S-II)-HA 
concentrations, will thus be favorable environments for the binding of $\mathrm{As}$ (III) to HA. In contrast, in oxidized environments with the development of $\mathrm{Fe}(\mathrm{III})$ species, $\mathrm{As}(\mathrm{III}, \mathrm{V})$ is expected to be strongly bound to $\mathrm{OM}$ via ternary complexes with $\mathrm{Fe}(\mathrm{III})$ as cationic or (nano)oxides bridges [5,71-73]. Under reducing conditions, where $\mathrm{Fe}(\mathrm{III})$ is reduced to $\mathrm{Fe}(\mathrm{II})$, this mechanism will not be activated and the binding of $\mathrm{As}$ (III) to OM will thus predominantly occur through the direct binding of $\mathrm{As}(\mathrm{III})$ by thiol groups. However, in organic-rich environments such as wetland soils, Fe(II) is strongly bound to OM [44,74-76]. Therefore, several questions can be raised regarding the binding of $A s$ to $O M$ in these environments, such as: can the Fe(II) bound to OM modify the As binding? Is it possible to form ternary complexes between $\mathrm{As}(\mathrm{III}), \mathrm{Fe}(\mathrm{II})$ and OM? If so, what is the dominant mechanism that binds As(III) to OM in these types of environments: As(III)-Fe(II)-HA or to As(III)-S(-II)-HA?

\section{Conclusion and perspectives}

We provided experimental data for As(III) binding by Leonardite that has either been grafted or not with thiol groups. Titrations of both HAs were used to calculate the protonation/deprotonation parameters of each thiol site defined in our modified PHREEQCModel VI model. In a second step, As(III)-HA experimental sorption isotherms were fitted to determine the binding parameters of the As(III)-thiol HA complexes. Two binding hypotheses were tested, the establishment of monodentate complexes (the Mono model) and the formation of tridentate complexes (the Tri model). To test each of these models, the extrapolated binding parameter sets of the Mono and Tri models were used to fit several experimental datasets available in the literature. This procedure could be used to validate the Mono model, i.e. the monodentate hypothesis, in terms of its ability to predict As(III) binding by HA. Extrapolated log $\mathrm{K}_{\mathrm{MS}}$ was equal to $2.91 \pm 0.04$. When the amount of bound As(III) to HA was low (around $5-10 \%$ of $\mathrm{As}(\mathrm{III})$ bound to HA in these experimental conditions), they were strongly dependent on the thiol density. The formation of monodentate complexes rather than tridentate ones could be explained by the combination of the low thiol density and the relative rigidity of $\mathrm{HA}$ forming molecules conferred by their abundance in aromatic rings, 
in contrast to flexible peptides or proteins, which are able to bind As(III) through tridentate complexes with thiol functions. These results therefore highlighted the necessity to determine the concentration of $S$ and more specifically the concentration of the thiol groups in the different organic matters, which is currently not easily determined. It could also be interesting to study the binding of As(III) by fulvic acids, which have a smaller aromatic nucleus and a long aliphatic chain, to better constrain the fate of $A s(I I I)$ in organic-rich environments. Moreover, the binding by Fe through ternary complexes should be better defined to determine the competition between both mechanisms in the different redox states of As and Fe. 


\section{Acknowledgments}

This study was funded by the French ANR through the "Programme Jeunes Chercheurs" ARSENORG. Dr S. Mullin is acknowledged for post-editing the English style. We also acknowledge D. G. Kinniburgh for his program writing help. 


\section{References}

[1] J.A. Plant, D.G. Kinniburgh, P.L. Smedley, F.M. Fordyce, in:, Treatise Geochem., Elsevier, 2004, pp. 17-66.

[2] H. Guo, B. Zhang, Y. Zhang, Appl. Geochem. 26 (2011) 360.

[3] M. Bauer, C. Blodau, Sci. Total Environ. 354 (2006) 179.

[4] M. Bauer, C. Blodau, Geochim. Cosmochim. Acta 73 (2009) 529.

[5] K. Ritter, G. Aiken R., J.F. Ranville, M. Bauer, D.L. Macalady, Environ. Sci. Technol. 40 (2006) 5380.

[6] S. Fendorf, Lawrence Berkeley Natl. Lab. (2010).

[7] B.D. Kocar, Soil-Sediment Processes Perpetuating History's Largest Mass Poisoning through Release of Arsenic to Asian Groundwaters, ProQuest, 2008.

[8] M.L. Polizzotto, C.F. Harvey, S.R. Sutton, S. Fendorf, Proc. Natl. Acad. Sci. U. S. A. 102 (2005) 18819.

[9] J. Akai, K. Izumi, H. Fukuhara, H. Masuda, S. Nakano, T. Yoshimura, H. Ohfuji, H. Md Anawar, K. Akai, Appl. Geochem. 19 (2004) 215.

[10] F.S. Islam, A.G. Gault, C. Boothman, D.A. Polya, J.M. Charnock, D. Chatterjee, J.R. Lloyd, Nature 430 (2004) 68.

[11] J.. McArthur, D.. Banerjee, K.. Hudson-Edwards, R. Mishra, R. Purohit, P. Ravenscroft, A. Cronin, R.. Howarth, A. Chatterjee, T. Talukder, D. Lowry, S. Houghton, D.. Chadha, Appl. Geochem. 19 (2004) 1255.

[12] J.M. McArthur, P. Ravenscroft, S. Safiulla, M.F. Thirlwall, Water Resour. Res. 37 (2001) 109.

[13] K.J. Tufano, C. Reyes, C.W. Saltikov, S. Fendorf, Environ. Sci. Technol. 42 (2008) 8283.

[14] M. Grafe, M.J. Eick, P.R. Grossl, Soil Sci. Soc. Am. J. 65 (2001) 1680.

[15] I. Ko, J.-Y. Kim, K.-W. Kim, Colloids Surf. Physicochem. Eng. Asp. 234 (2004) 43.

[16] A.D. Redman, D.L. Macalady, D. Ahmann, Environ. Sci. Technol. 36 (2002) 2889.

[17] P. Thanabalasingam, W.F. Pickering, Environ. Pollut. 12 (1986) 233.

[18] P. Warwick, E. Inam, N. Evans, Environ. Chem. 2 (2005) 119.

[19] J. Buschmann, A. Kappeler, U. Lindauer, D. Kistler, M. Berg, L. Sigg, Environ. Sci. Technol. 40 (2006) 6015.

[20] V. Lenoble, D.H. Dang, M. Loustau Cazalet, S. Mounier, H.-R. Pfeifer, C. Garnier, Talanta 134 (2015) 530.

[21] A.F. Holleman, E. Wiberg, Lehrbuch Der Anorganischen Chemie, 101st ed., W. deGruyter, 1995.

[22] G. Liu, Y. Cai, Chemosphere 81 (2010) 890.

[23] H. Fakour, T.-F. Lin, J. Hazard. Mater. 279 (2014) 569.

[24] P. Langner, C. Mikutta, R. Kretzschmar, Nat. Geosci. 5 (2011) 66.

[25] M. Hoffmann, C. Mikutta, R. Kretzschmar, Environ. Sci. Technol. 46 (2012) 11788.

[26] S. Cavanillas, E. Chekmeneva, C. Ariño, J.M. Díaz-Cruz, M. Esteban, Anal. Chim. Acta 746 (2012) 47.

[27] B.P. Gaber, A.L. Fluharty, Bioinorg. Chem. 2 (1972) 135.

[28] K.T. Kitchin, K. Wallace, J. Inorg. Biochem. 102 (2008) 532.

[29] N.A. Rey, O.W. Howarth, E.C. Pereira-Maia, J. Inorg. Biochem. 98 (2004) 1151.

[30] A.M. Spuches, H.G. Kruszyna, A.M. Rich, D.E. Wilcox, Inorg. Chem. 44 (2005) 2964.

[31] J. Starý, J. Růzicka, Talanta 15 (1968) 505.

[32] W.L. Zahler, W.W. Cleland, J. Biol. Chem. 243 (1968) 716.

[33] L. Zhao, S. Chen, L. Jia, S. Shu, P. Zhu, Y. Liu, Metallomics 4 (2012) 988.

[34] A.W.P. Vermeer, W.H. Van Riemsdijk, L.K. Koopal, Langmuir 14 (1998) 2810.

[35] M.J. Avena, L.K. Koopal, W.H. Van Riemsdijk, J. Colloid Interface Sci. 217 (1999) 37.

[36] M. Fakih, M. Davranche, A. Dia, B. Nowack, G. Morin, P. Petitjean, X. Châtellier, G. Gruau, Chem. Geol. 259 (2009) 290.

[37] E. Tipping, Aquat. Geochem. 4 (1998) 3. 
[38] N.J. McSweeney, L. Forbes, Miner. Eng. 64 (2014) 67.

[39] M. Hoffmann, C. Mikutta, R. Kretzschmar, Environ. Sci. Technol. 48 (2014) 3822.

[40] C. Appelo, D. Postma, Geochemistry, Groundwater and Pollution, Taylor \& Francis, New York, 2005.

[41] D.J. Liu, C. Bruggeman, N. Maes, Radiochim. Acta 96 (2008).

[42] R. Marsac, N.L. Banik, C.M. Marquardt, J.V. Kratz, Geochim. Cosmochim. Acta 131 (2014) 290.

[43] R. Marsac, M. Davranche, G. Gruau, M. Bouhnik-Le Coz, A. Dia, Geochim. Cosmochim. Acta 75 (2011) 5625.

[44] C. Catrouillet, M. Davranche, A. Dia, M. Bouhnik-Le Coz, R. Marsac, O. Pourret, G. Gruau, Chem. Geol. 372 (2014) 109.

[45] J. Lützenkirchen, J. van Male, F. Leermakers, S. Sjöberg, J. Chem. Eng. Data 56 (2011) 1602.

[46] J. Lützenkirchen, J. Colloid Interface Sci. 217 (1999) 8.

[47] D.G. Kinniburgh, W.H. van Riemsdijk, L.K. Koopal, M. Borkovec, M.F. Benedetti, M.J. Avena, Colloids Surf. Physicochem. Eng. Asp. 151 (1999) 147.

[48] E.M. Thurman, Organic Geochemistry of Natural Waters, 1985.

[49] J.P. Gustafsson, J. Colloid Interface Sci. 244 (2001) 102.

[50] E. Tipping, M.A. Hurley, Geochim. Cosmochim. Acta 56 (1992) 3627.

[51] M. Haitzer, G.R. Aiken, J.N. Ryan, Environ. Sci. Technol. 37 (2003) 2436.

[52] J. Qian, U. Skyllberg, W. Frech, W.F. Bleam, P.R. Bloom, P.E. Petit, Geochim. Cosmochim. Acta 66 (2002) 3873.

[53] B. Rao, C. Simpson, H. Lin, L. Liang, B. Gu, Talanta 119 (2014) 240.

[54] K. Xia, F. Weesner, W.F. Bleam, P.R. Bloom, U.L. Skyllberg, P.A. Helmke, Soil Sci. Soc. Am. J. 62 (1998) 1240.

[55] W. Dong, L. Liang, S. Brooks, G. Southworth, B. Gu, Environ. Chem. 7 (2010) 94.

[56] A. Manceau, K.L. Nagy, Geochim. Cosmochim. Acta 99 (2012) 206.

[57] T. Jiang, U. Skyllberg, S. Wei, D. Wang, S. Lu, Z. Jiang, D.C. Flanagan, Geochim. Cosmochim. Acta 154 (2015) 151.

[58] A. Kappeler, Arsenic Binding to Dissolved Humic Acids in Aqueous Solution, ETHZ, 2006.

[59] J.-I. Kim, G. Buckau, G.H. Li, H. Duschner, N. Psarros, Fresenius J. Anal. Chem. 338 (1990) 245.

[60] C. Arnold, A. Ciani, S.R. Müller, A. Amirbahman, R.P. Schwarzenbach, Environ. Sci. Technol. 32 (1998) 2976.

[61] C.J. Milne, D.G. Kinniburgh, E. Tipping, Environ. Sci. Technol. 35 (2001) 2049.

[62] M. Pédrot, A. Dia, M. Davranche, J. Colloid Interface Sci. 339 (2009) 390.

[63] J. Buffle, K.J. Wilkinson, S. Stoll, M. Filella, J. Zhang, Environ. Sci. Technol. 32 (1998) 2887.

[64] C.J. Milne, D.G. Kinniburgh, W.H. Van Riemsdijk, E. Tipping, Environ. Sci. Technol. 37 (2003) 958.

[65] G. Sposito, CRC Crit. Rev. Environ. Control 16 (1986) 193.

[66] A.E. Martell, R.M. Smith, Critical Stability Constants, 1989.

[67] H.-T. Lin, M.. Wang, G.-C. Li, Chemosphere 56 (2004) 1105.

[68] M. Hoffmann, C. Mikutta, R. Kretzschmar, Environ. Sci. Technol. 47 (2013) 12165.

[69] P. Langner, C. Mikutta, R. Kretzschmar, Nat. Geosci. 5 (2011) 66.

[70] X. Liang, D.G. Drueckhammer, New J. Chem. 38 (2014) 1368.

[71] C. Mikutta, J. Frommer, A. Voegelin, R. Kaegi, R. Kretzschmar, Geochim. Cosmochim. Acta 74 (2010) 5574.

[72] C. Mikutta, R. Kretzschmar, Environ. Sci. Technol. 45 (2011) 9550.

[73] P. Sharma, J. Ofner, A. Kappler, Environ. Sci. Technol. 44 (2010) 4479.

[74] A.L. Rose, T.D. Waite, Mar. Chem. 84 (2003) 85.

[75] M. Schnitzer, S.I.M. Skinner, Soil Sci. 102 (1966) 361.

[76] T.L. Theis, P.C. Singer, Environ. Sci. Technol. 8 (1974) 569.

[77] J.T. Edsall, J. Wyman, Biophysical Chemistry, Academic Press, New York, 1958. 
[78] J.D. Gough, J.M. Gargano, A.E. Donofrio, W.J. Lees, Biochemistry (Mosc.) 42 (2003) 11787.

[79] R. Williams, (n.d.).

[80] A.M. Spuches, H.G. Kruszyna, A.M. Rich, D.E. Wilcox, Inorg. Chem. 44 (2005) 2964.

[81] A.M. Spuches, D.E. Wilcox, J. Am. Chem. Soc. 130 (2008) 8148. 


\section{Figures}

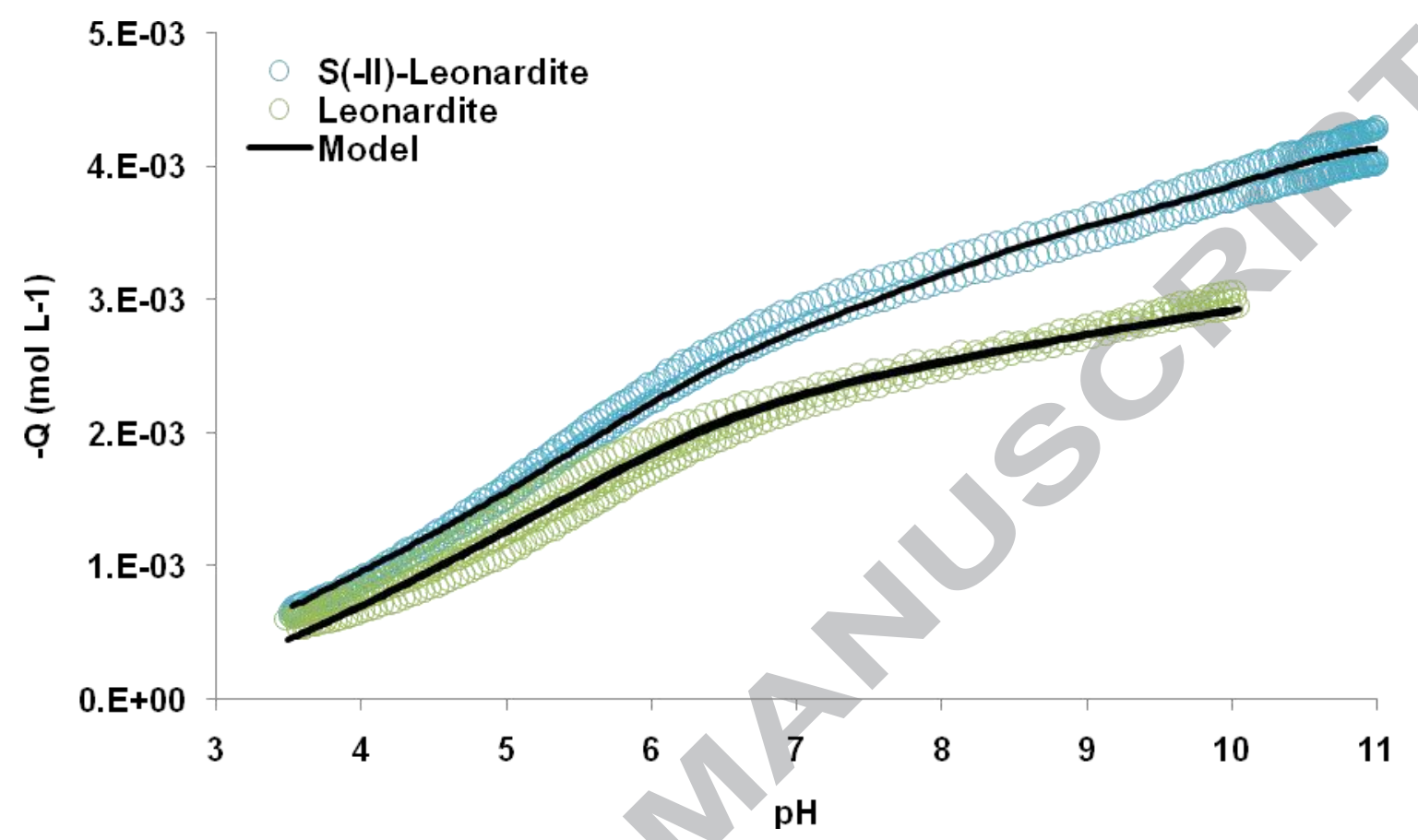

Fig. 1: Titrations of Leonardite (shown as green symbols) and S(-II)-Leonardite (shown as blue symbols) as compared to the modeling (shown as black lines). 

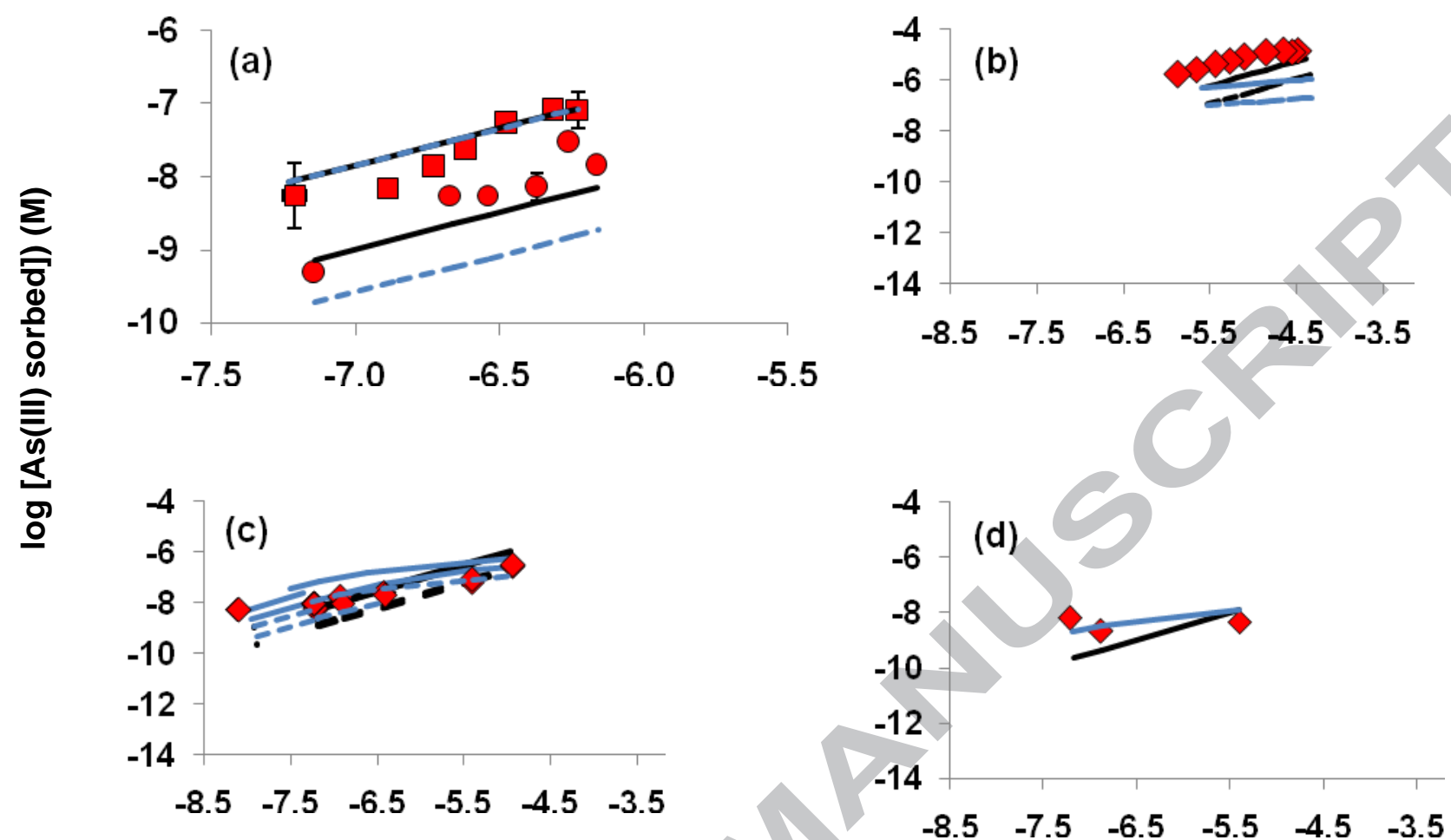

$\log [$ As(III) free]) (M)
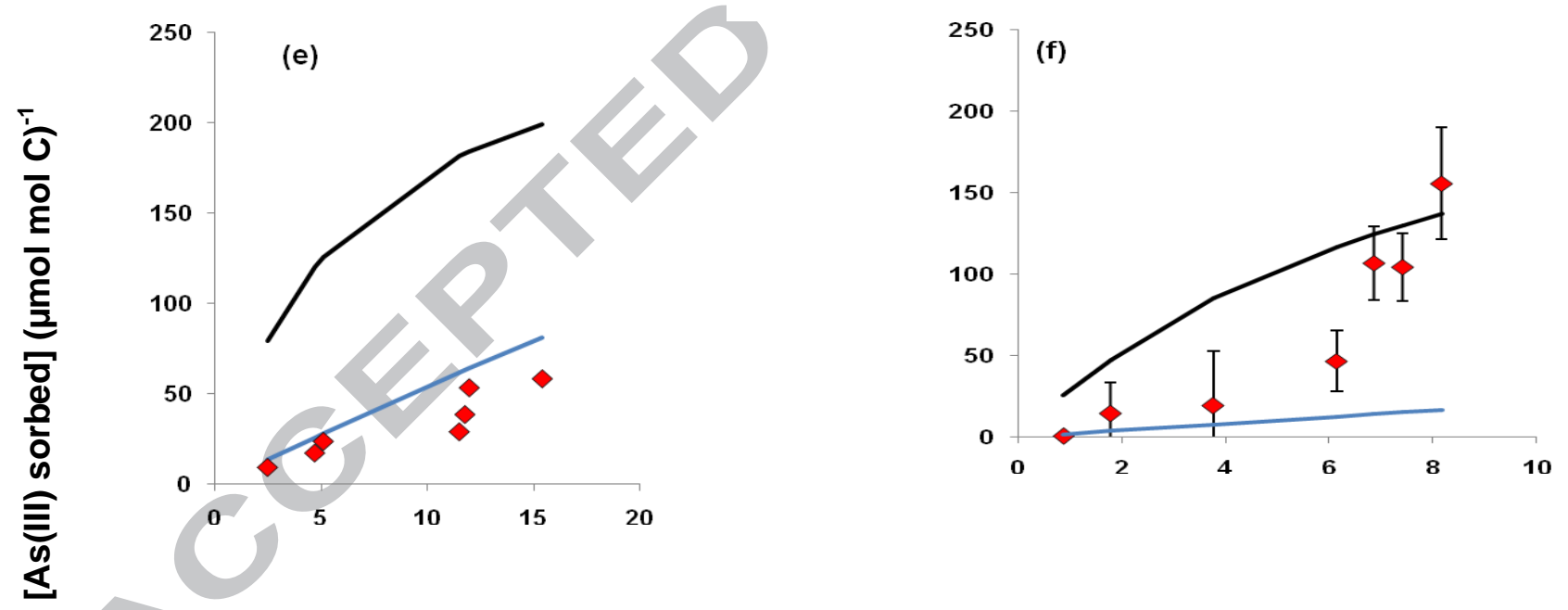

Legend:

S content (mmol mol $\mathrm{C}^{-1}$ )

- Experimental data

- Leonardite

- S(-II)-Leonardite 


\section{Tri model nS=50\%*Stot - Mono model nS=50\%*Stot \\ ---- Tri model nS=10\%*Stot ---- Mono model nS=10\%*Stot}

Fig. 2: Experimental and modeled datasets of (a) Leonardite and S(-II)-Leonardite, (b) the present purified Aldrich HA, (c) AHA experimental data from Kappeler [58], (d) SRHA experimental data from Kappeler [58], (e) HA experimental data from Hoffmann et al. [25] , (f) peat experimental data from Hoffmann et al. [25]. 


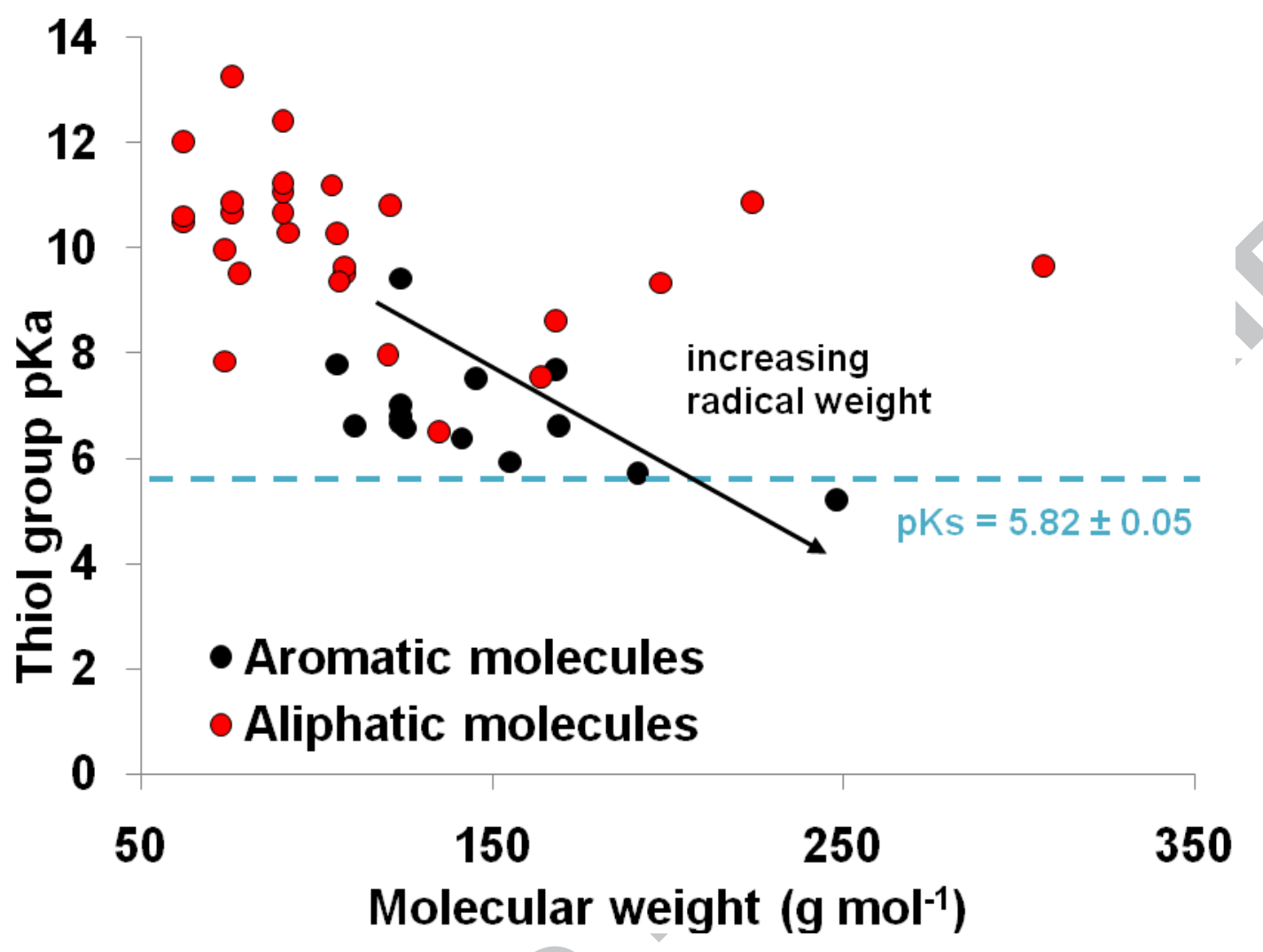

Fig. 3: Compilation of the pKa of the thiol function of thiol-containing organic molecules according to their molecular weight $[66,77-79]$. The distinction was made between aliphatic (red symbols) and aromatic ring-containing molecules (black symbols). 


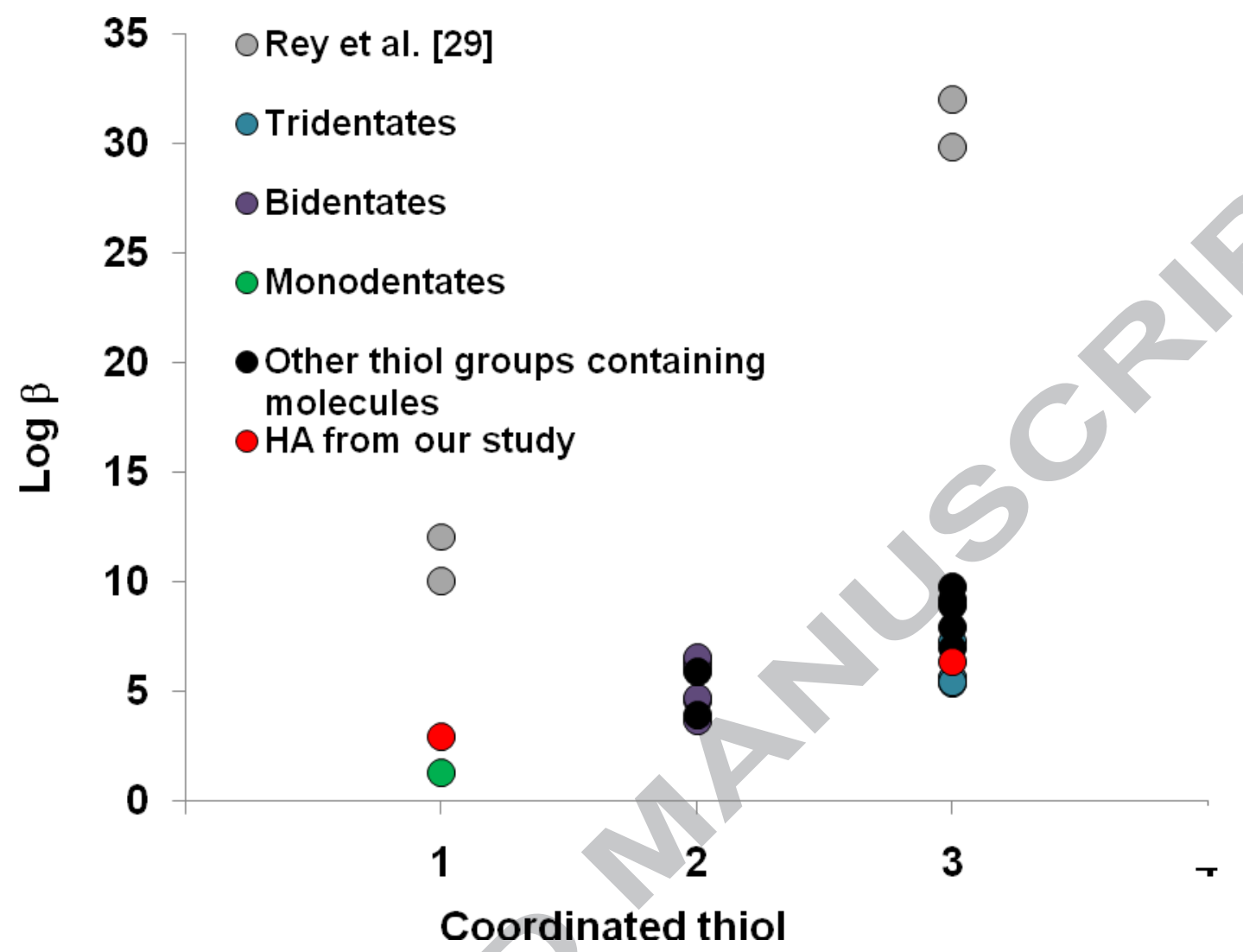

Fig. 4: Comparison between $\log \beta$ of thiol-containing organic molecules and $A s(I I I)$ and log $\mathrm{K}_{\mathrm{MS}}$ relative to the number of coordinated thiols in the complexes [26,27,29,31-33,39,80,81]. 


\section{Tables}

Table 1: Summary of the different parameters of the model.

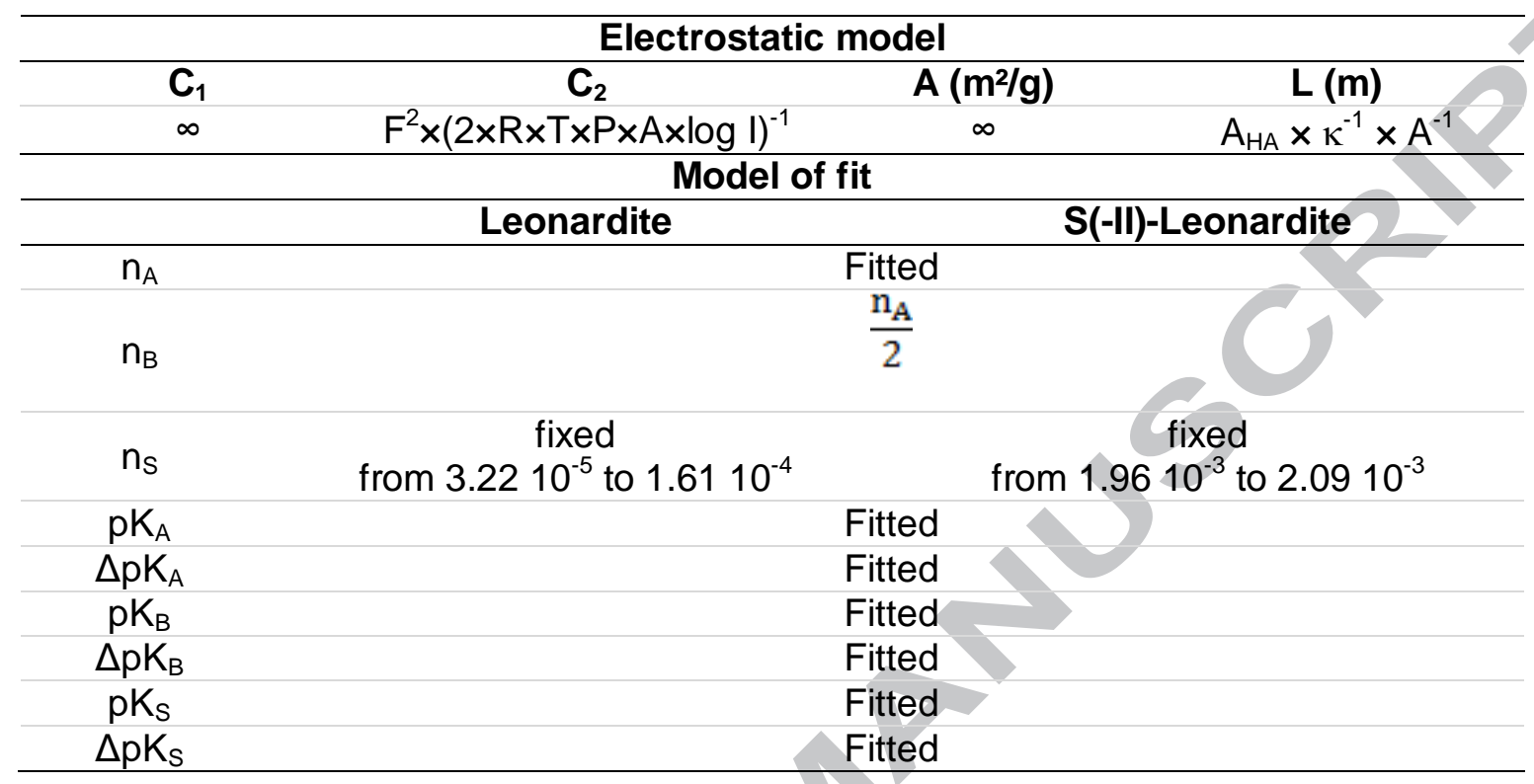


Table 2: Values of the protonation/deprotonation parameters of the three sites (A: carboxylic groups, B phenolic groups and $\mathrm{S}$ thiol groups). Values in bold are fixed.

\begin{tabular}{|c|c|c|c|c|c|c|}
\hline & $n_{s}=10 \% * S_{t o t}$ & $n_{S}=20 \% * S_{\text {tot }}$ & $\mathrm{n}_{\mathrm{S}}=30 \% * \mathrm{~S}_{\mathrm{tot}}$ & $\mathrm{n}_{\mathrm{S}}=40 \%{ }^{*} \mathrm{~S}_{\mathrm{tot}}$ & $n_{\mathrm{S}}=50 \%{ }^{*} S_{\text {tot }}$ & $\begin{array}{l}\text { Tipping et al. } \\
\text { [37] (Table V) }\end{array}$ \\
\hline $\mathbf{n}_{\mathrm{A}}$ & $\begin{array}{c}2.0110^{-3} \pm 3 \\
10^{-5}\end{array}$ & $\begin{array}{c}1.9910^{-3} \pm 2 \\
10^{-4}\end{array}$ & $\begin{array}{c}1.9710^{-3} \pm 3 \\
10^{-5}\end{array}$ & $\begin{array}{c}1.9610^{-3} \pm 8 \\
10^{-5}\end{array}$ & $\begin{array}{c}1.9410^{-3} \pm 3 \\
10^{-5}\end{array}$ & $\begin{array}{c}2.510^{-3}-4.3 \\
10^{-3}\end{array}$ \\
\hline $\mathrm{pK}_{\mathrm{A}}$ & $4.26 \pm 0.02$ & $4.26 \pm 0.03$ & $4.26 \pm 0.02$ & $4.28 \pm 0.03$ & $4.28 \pm 0.03$ & $3.8-4.3$ \\
\hline$\Delta \mathrm{pK}_{\mathrm{A}}$ & $2.11 \pm 0.08$ & $2.12 \pm 0.09$ & $2.10 \pm 0.09$ & $2.13 \pm 0.10$ & $2.14 \pm 0.11$ & $0.1-3.4$ \\
\hline$n_{B}$ & $0.5 n_{A}$ & $0.5 \mathrm{n}_{\mathrm{A}}$ & $0.5 \mathrm{n}_{\mathrm{A}}$ & $0.5 n_{A}$ & $0.5 \mathrm{n}_{\mathrm{A}}$ & $0.5 \mathrm{nA}$ \\
\hline $\mathrm{pK}_{\mathrm{B}}$ & $7.12 \pm 0.15$ & $7.10 \pm 0.15$ & $7.07 \pm 0.16$ & $7.11 \pm 0.26$ & $7.10 \pm 0.16$ & $8.3-8.9$ \\
\hline$\Delta \mathrm{pK}_{\mathrm{B}}$ & $3.33 \pm 0.23$ & $3.41 \pm 0.12$ & $3.36 \pm 0.23$ & $3.52 \pm 0.49$ & $3.57 \pm 0.10$ & $3-4.6$ \\
\hline $\mathrm{n}_{\mathrm{s}}$ & $3.2210^{-5}$ & $6.4410^{-5}$ & $9.6610^{-5}$ & $1.2910^{-4}$ & $1.6110^{-4}$ & \\
\hline $\mathrm{n}_{\mathrm{s}}^{\prime}$ & $1.9610^{-3}$ & $2.0010^{-3}$ & $2.0310^{-3}$ & $2.0610^{-3}$ & $2.0910^{-3}$ & \\
\hline $\mathrm{pK}_{\mathrm{s}}$ & $5.82 \pm 0.04$ & $5.84 \pm 0.04$ & $5.84 \pm 0.04$ & $5.82 \pm 0.05$ & $5.82 \pm 0.04$ & determined \\
\hline$\Delta \mathrm{pK}_{\mathrm{S}}$ & $6.14 \pm 0.14$ & $6.12 \pm 0.14$ & $6.15 \pm 0.14$ & $6.12 \pm 0.12$ & $6.12 \pm 0.14$ & \\
\hline RMSE & 0.03 & 0.03 & 0.03 & 0.03 & 0.03 & \\
\hline
\end{tabular}


Table 3: Abundances calculated for the datasets from the literature and RMSE calculated using the Mono and Tri models.

\begin{tabular}{|c|c|c|c|c|}
\hline & $\mathrm{n}_{\mathrm{s}}\left(\mathrm{mol} \mathrm{g}^{-1}\right)$ & Number of data & Monodentates & Tridentates \\
\hline PAHA & \multirow{4}{*}{$7.2810^{-5}$ to $3.6410^{-4}$} & 30 & 0.67 & 0.90 \\
\hline Present study & & 7 & 0.86 & 0.62 \\
\hline [17] & & 9 & 0.73 & 1.24 \\
\hline [18] & & 14 & 0.53 & 0.82 \\
\hline AHA & \multirow{7}{*}{$1.3110^{-4}$ to $6.5610^{-4}$} & 71 & 0.90 & 1.56 \\
\hline [58] & & 16 & 0.51 & 0.40 \\
\hline [22] $\mathrm{pH}=5.2$ & & 8 & 0.52 & 0.31 \\
\hline [22] $\mathrm{pH}=7$ & & 7 & 0.56 & 0.57 \\
\hline [22] $\mathrm{pH}=9$ & & 7 & 1.73 & 4.12 \\
\hline$[23] \mathrm{pH}=7.5$ & & 27 & 1.16 & 2.22 \\
\hline [17] & & 6 & 0.67 & 1.52 \\
\hline SRHA & \multirow{3}{*}{$3.9810^{-5}$} & 5 & 1.71 & 0.45 \\
\hline [58] & & 3 & 0.96 & 0.39 \\
\hline [20] & & 2 & 2.83 & 0.54 \\
\hline Others & & 14 & 0.75 & 0.46 \\
\hline [25] Elliot Soil & $1.1410^{-4}$ to $7.0610^{-4}$ & 7 & 0.74 & 0.19 \\
\hline \multirow[t]{3}{*}{ [25] Peat } & $3.8610^{-5}$ to $3.6110^{-4}$ & 7 & 0.77 & 0.72 \\
\hline & Weighted RMSE & 120 & 0.86 & 1.22 \\
\hline & $\begin{array}{l}\text { PAHA and AHA } \\
\text { weighted RMSE } \\
\text { without basic pH }\end{array}$ & 60 & 0.60 & 0.75 \\
\hline
\end{tabular}


Table 4: Log $\mathrm{K}_{\mathrm{MS}}$ determined from the Mono and Tri models.

\begin{tabular}{lcccc}
\cline { 2 - 5 } & \multicolumn{2}{c}{ Monodentates } & \multicolumn{2}{c}{ Tridentates } \\
& $\log \mathbf{K}_{\text {MS }}$ & RMSE & log $\mathbf{K}_{\text {MS }}$ & RMSE \\
\hline $\mathbf{n}_{\mathbf{S}}=\mathbf{1 0 \%}{ }^{*} \mathbf{S}_{\text {tot }}$ & $2.93 \pm 0.04$ & 0.72 & $2.93 \pm 0.11$ & 0.46 \\
$\mathbf{n}_{\mathbf{S}}=\mathbf{2 0 \%}{ }^{*} \mathbf{S}_{\text {tot }}$ & $2.92 \pm 0.04$ & 0.54 & $2.35 \pm 0.06$ & 0.33 \\
$\mathbf{n}_{\mathbf{S}}=\mathbf{3 0 \%}{ }^{*} \mathbf{S}_{\text {tot }}$ & $2.92 \pm 0.04$ & 0.43 & $2.24 \pm 0.04$ & 0.30 \\
$\mathbf{n}_{\mathbf{S}}=\mathbf{4 0 \%}{ }^{*} \mathbf{S}_{\text {tot }}$ & $2.91 \pm 0.04$ & 0.37 & $2.17 \pm 0.03$ & 0.28 \\
$\mathbf{n}_{\mathbf{S}}=\mathbf{5 0 \%}{ }^{*} \mathbf{S}_{\text {tot }}$ & $2.91 \pm 0.03$ & 0.33 & $2.12 \pm 0.02$ & 0.27 \\
\hline
\end{tabular}


Graphical abstract

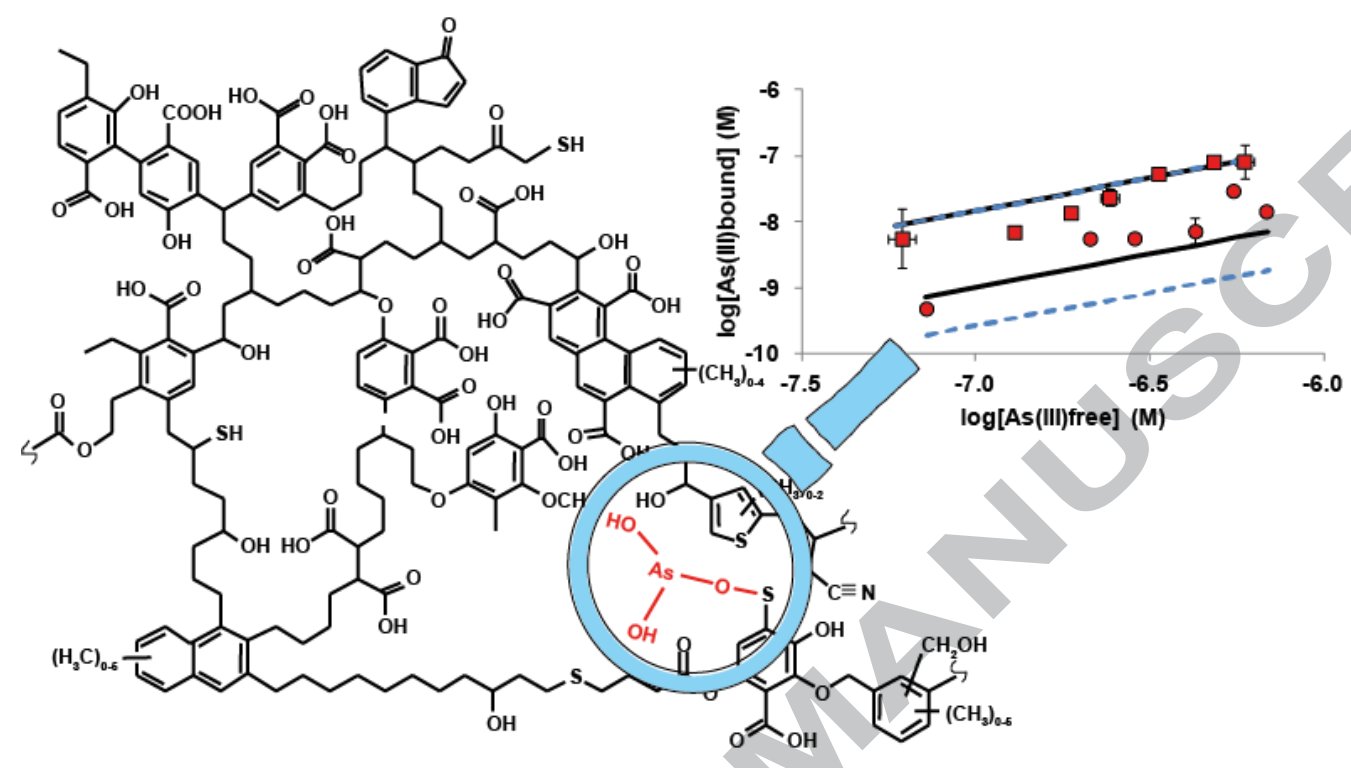

